\title{
Sobre el tiempo: Rutina, flexibilidad y tiempo cotidiano en barrio Cristo Rey y barrio Escalante (2011-2014)
}

Recibido: 3 de agosto 2020 Revisado: 25 de mayo 2021 Aprobado: 21 de junio 2021

Paulo Coto Murillo Costarricense. Tiene una maestría en Sociología por la Universidad de Costa Rica. Es investigador en el Centro de Investigación en Cultura y Desarrollo (UNED, Costa Rica) y profesor en la Maestría Centroamericana en Sociología por la Universidad de Costa Rica (Costa Rica). Ha trabajado temas relacionados a discursos y representaciones sobre la pobreza, reproducción cultual en el capitalismo, ideología y hegemonía, sociología de las religiones, sociología urbana, derecho a la cuidad, convivencia urbana, bienes comunes e industrias culturales. Correo electrónico: pcoto@uned.ac.cr

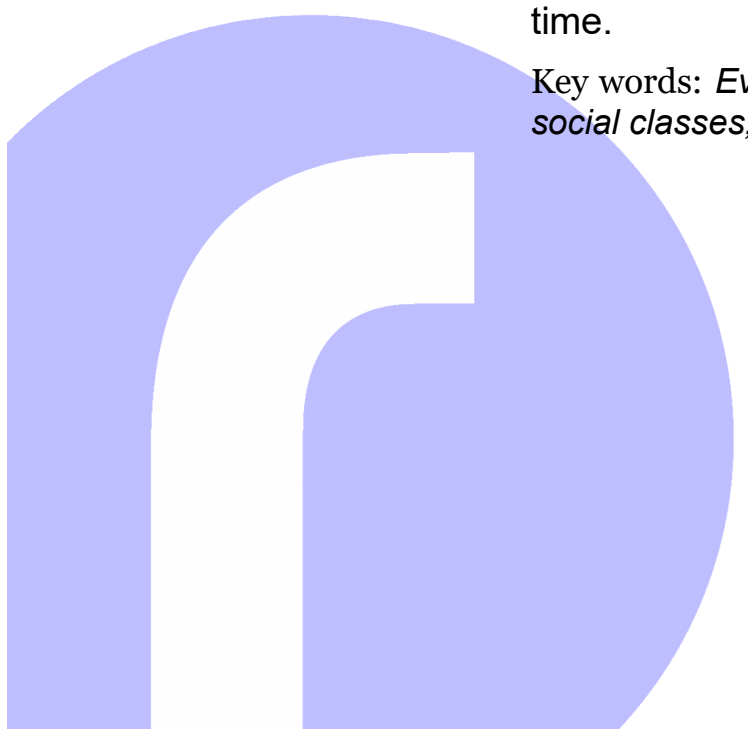

https://revistas.uned.ac.cr/index.php/rupturas (c) (1)(2) time.
Resumen: Este artículo discute la estructura temporal de la vida cotidiana en dos barrios históricos de la ciudad de San José. Estos barrios son barrio Cristo Rey y barrio Escalante. Se muestra cómo esta estructura o arquitectura se comporta como una economía política del tiempo. La lógica que organiza el tiempo diario en ambos espacios del vecindario es la división social del trabajo y la división social del género. También, el trabajo de investigación evidencia que las personas habitantes de Cristo Rey experimentan una temporalidad rutinaria; en tanto, aquellas que viven en barrio Escalante lo hacen bajo la egida de un tiempo flexible.

Palabras clave: vida cotidiana; arquitectura del tiempo, uso del tiempo, intercambio del tiempo, clases sociales, rutina, flexibilidad

\section{About Time: Routine, Flexibility and Daily Time in Cristo Rey Neighborhood and Escalante Neighborhood (2011-2014)}

Abstract: This article discusses the temporal structure of daily life in two historical neighborhoods in San José City. These neighborhoods are Cristo Rey and Escalante. This paper shows how this structure or architecture behaves like a political time-economy through the time. The logic that organizes daily time in both neighborhood spaces is the social division of labor and the social division of gender. The article also shows that the people who live in Cristo Rey experiment daily routine. And those who live in Escalante neighborhood have flexible

Key words: Everyday life, architecture of time, use of time, exchange of time, social classes, gender, routine, flexibility 
"El hombre existe sólo parte del tiempo, durante los días de trabajo, como instrumento de la actuación enajenada; el resto del tiempo es li-

bre para sí mismo (si el día medio de trabajo, incluyendo la preparación y la transportación, es de diez horas, y si las necesidades biológicas de dormir y alimentarse requieren otras diez horas, el tiempo libre será de cuatro horas en cada veinticuatro durante la mayor parte de la vida del individuo" (Marcuse 1970, 55).

1. Este artículo se desprende como resultado de la investigación: "Convivencia urbana en la ciudad de San José. Un estudio sobre las prácticas y proyecciones diarias de los y las habitantes del barrio Cristo Rey y barrio Escalante". El trabajo se dispuso como un estudio de caso comparativo, el cual se focalizó en las prácticas de convivencia, participación y organización barrial partiendo de los ritmos de vida cotidiana de ambos espacios urbanobarriales referidos. Asimismo, el estudio fue realizado desde el Centro de Investigación en Cultura y Desarrollo de 2011 a 2014, centro perteneciente a la Universidad Estatal a Distancia en Costa Rica.

\section{Introducción ${ }^{1}$}

Antes de internarnos en la descripción y el análisis del estudio del tiempo de la vida cotidiana, es oportuno señalar que la siguiente reflexión corresponde al producto de un proceso de investigación que indagó la realidad espacial urbana de la ciudad de San José al partir de dos barrios históricos y céntricos, ambos cercanos al centro de poder político y económico de la capital: barrio Cristo Rey y barrio Escalante. Uno y otro representan escenarios urbanos que expresan el devenir de la ciudad y de la formación social en su impronta económica capitalistas -clasista, desigual, segregada, empobrecidaes por tanto que, cuando llegue el momento de profundizar en la labor de análisis de la vida cotidiana no se hará más que abordar la vida de las personas que habitan estos barrios y, por tanto, de las personas que conciben, perciben y viven la ciudad (Lefebvre 2006).

El artículo, entonces, ahondará en sus primeros apartados en las descripciones de rigor académicas exigidas: un breve encuadre histórico de ambos barrios, datos demográficos y un breve esbozo de la metodología desplegada en la recolección de datos y en sus análisis. Posterior a ello, se avanza en la presentación de algunas reflexiones teóricas sobre el tiempo, sobre su uso y sus lógicas de intercambio en la sociedad contemporánea para desde ahí pensar la vida cotidiana que se despliega y se registra en los barrios al partir de las narrativas y las vivencias de sus habitantes de la racionalidad y emotividad que le imprimen, a la temporalidad impuesta, sus ritmos, ciclos, rutinas y voluntades.

La descripción, el análisis y la reflexión, de lo último que ha sido descrito y mencionado en el párrafo anterior, correspondería a las parte sustantiva de este trabajo, la cual se propone crear un juego comparativo que demuestre la tensión y la dialéctica de las semejanzas y las diferencias entre ambos espacios barriales, así como los hilos que los unen y los articulan en sus estructuras temporales, una suerte de estructura política del tiempo que enfatiza en la intersección entre la clase y el género. Derivado de este recorrido, el presente trabajo cerraría con la presentación de las conclusiones. A continuación, se reconocen los elementos históricos de barrio Cristo Rey y barrio Escalante. 


\section{Breve pasaje por el tránsito histórico de barrio Cristo Rey y barrio Escalante}

Precisar el nacimiento de cualquier fenómeno social siempre es una tarea compleja, más cuando se trata de determinar hechos que discurren en el margen excluido de la sociedad. Barrio Cristo Rey es un ejemplo de lo anterior; además, señala y devela configuraciones asociadas a la producción del espacio social en el tiempo histórico.

Lo que hoy es conocido como bario Cristo Rey, en sus orígenes, fue reconocido como El laberinto o barrio El laberinto y, posteriormente, como barrio Keith. No cabe duda y, por tanto, se puede afirmar que Cristo Rey es una objetivación socio-espacial de los primeros procesos de expansión de la ciudad de San José, que, como lo demuestra el barrio actualmente, expresó procesos de empobrecimiento acompañado de un ethos popular; por lo tanto, la razón urbanística del Estado no actuó más que bajo la impronta del abandono y la exclusión (Quesada 2011).

Este proceso espacial brevemente descrito remonta al siglo XIX y a la aparición de los primeros anillos de miseria en el sur de la ciudad capital; justamente, entre 1871 a 1875 se conformó barrio Cristo Rey; no obstante, la consolidación de Cristo Rey como paisaje barrial se dio con la construcción del ferrocarril al Pacífico en $1910^{2}$ y la correspondiente edificación de la estación de trenes (Botey 1999 y Rodríguez 2000, Carvajal 2005).

2. En 1910, los terrenos del "Barrio el Laberinto" son comprados por el señor John M. Keith Faulkner, es justo en ese momento, cuando empieza

Este acontecimiento marcó de forma definitiva la impronta obrera y popular hacer llamado como "la gente del barrio, dado que Cristo Rey empezó a ser habitado por personas campe- de los lotes de Keith" y luego sinas, desplazadas o expulsados del campo, migrantes sin documentos, za- Keith" (Álvarez 1996; Cruz, pateros, limpiabotas, sastres, lavanderas, trabajadores del tren, obreros de 1995.; Rodríguez 2000). construcción y grupos de personas empobrecidas provenientes de otros barrios de la ciudad. En esta misma época, y a tono con el carácter sociocultural y económico de sus habitantes, se suscitó el desarrollo de industrias de tejido, aserraderos y otras actividades económicas asociadas al dinamismo introducido por la estación del ferrocarril al Pacífico (COF 1978, Ramírez y Rodríguez 1999 y Rodríguez 2000).

En 1950, el barrio pasó a llamarse Barrio Cristo Rey en honor a su santo patrono, nombre que sobrevive hasta la actualidad. Algunos documentos señalan, sin que se tenga completa certeza, que el cambio fue propuesto y gestionado por la Curia Metropolitana con el beneplácito de las personas habitantes del barrio (Cruz 1995, Álvarez 1996, Ramírez y Rodríguez 1999, Solís y Coto 2014).

Finalmente, es relevante destacar que barrio Cristo Rey, históricamente, ha sido permeado por una sensibilidad política popular de izquierda. Prueba de ello es que, justo en los perímetros del este, se fundó el Partido Obrero Campesino, el cual tiempo después se convirtió en el Partido Comunista Costarri- 
cense (PCCR) Otro acontecimiento relevante consiste en que, en Cristo Rey, se ubicó la primera televisora nacional. (Rodríguez 2000, Solís y Coto 2014).

Si barrio Cristo Rey representó la expansión excluyente de la ciudad de San José en el siglo XIX, barrio Escalante significa su antítesis. Barrio Escalante surgió, entonces, como heredero de barrios paradigmáticos del distrito central del Carmen: Amón, Otoya y Aranjuez; barrios que marcaron la emergencia del San José elitista liberal del siglo XIX (Solís y Coto 2014).

Sin embargo, Barrio Escalante se constituyó espacialmente, a diferencia de Cristo Rey, en el siglo XX -entre las décadas de 1940 a 1950. Su nacimiento esta ligado a los ensanches privados no planificados de San José. Dicha expansión atrajo población migrante de alto ingresos, la cual se apropió de nuevos espacios que se tradujo en la segregación y la lotificación de los últimos vestigios de cafetales que rodeaban el casco de la ciudad capital hacia el noreste. Las conformaciones barriales elitistas como Dent, Alameda y los Yoses son ejemplos de esa expansión, que articuló San José con ciudades intermedias como San Pedro y Guadalupe (Carvajal 2005, 45).

Asimismo, con la constitución del Área Metropolitana de San José, entre las décadas de 1960 y 1970, el barrio empezó a alejarse poco a poco de su herencia asociada a la actividad económica de la Antigua Aduana y la estación de ferrocarriles del Atlántico arraigadas al siglo XIX. Así, se iniciaron las presiones e influencia de dinámicas económicas de carácter comercial y servicios de la Costa Rica del Estado Benefactor, las cuales impactaron y originaron modificaciones tantos en los usos sociales, culturales y espaciales del barrio (Solís y Coto 2014).

La potencia del empuje de esas lógicas económicas en el presente; ya bajo la impronta del capitalismo neoliberal, básicamente, se han asentado y han condicionado la producción del espacio en Escalante. El comercio, los servicios, el ocio, la cultural clasista y esnobista han dominado el uso y habitar del barrio al reconfigurarlo todo en el presente; por ejemplo, la Antigua Aduana se ha convertido en un teatro, la casa del ex presidente Rafael Ángel Calderón Guardia es hoy un museo y patrimonio arquitectónico; el Farolito y el Parque Francia son lugares de encuentro de personas, que recorren el barrio en busca de su amplia oferta estética, gastronómica y de bares. Barrio Escalante es más hoy una pieza de museo y artefacto cultural turístico, que un lugar donde las personas despliegan el trazo de sus historias familiares y personales.

\section{Caracterización socio-demográfica de los barrios}

Siguiendo con elementos contextuales, se presenta para ambos espacios barriales alguna información relevante de orden sociodemográficos correspondiente a los años del 2000 al 2011. La información, que se describirá y ex- 
pondrá, dará cuenta y ayudará a comprender el entorno cotidiano actual de barrio Cristo Rey y barrio Escalante.

Señalado lo anterior, el censo del año 2000 indica que, en barrio Cristo Rey, la mayoría de sus habitantes se ubicaban entre los 15 y 34 años (51\%). En barrio Escalante, en cambio, las personas adultas mayores son el segmento poblacional central con un $39 \%$ de habitantes; en tanto, para Cristo Rey este mismo grupo etario representaba el16, 2 \% de sus habitantes (INEC 2012, 2011).

Una década después, los datos del censo 2011 presentarán otra cara en relación con la composición demográfica. En ambos barrios, la población disminuyó significativamente: barrio Cristo Rey pasó de 7330 habitantes en el año 2000 a 5286 (-28\%); para el caso de barrio Escalante, se pasó de 1308 personas a $906(-30 \%)$. (INEC 2012, 2011) ${ }^{3}$.

Además, cuando se entra a observar el tema de migrantes es evidente que tanto Cristo Rey como Escalante presentan datos relevantes. Para el caso de barrio Cristo Rey, este segmento representó, en el 2000, 27,9 \% y en 2011 aumentó casi cinco puntos al pasar a $32,7 \%$ de sus habitantes. De este porcentaje, el 93,7 \% lo representan personas de origen nicaragüense y el resto de la población migrantes proviene del El Salvador $(2,14 \%)$ y Colombia $(1,07$ $\%)^{4}$.

Con respecto a barrio Escalante, la población migrante para el año 2000 era de 19,32\% aumentando levemente en 2011 a 22,1\%. La población nicaragüense es también mayoritaria con un 33,5\%; sin embargo, hay presencias significativas de otras nacionalidades como estadounidenses con un 11,6 \%, colombianas con un $11 \% \mathrm{y}$, finalmente, personas venezolanas y argentinas en un $7,3 \%$ y $6 \%$, respectivamente (INEC 2012, 2011).

En cuanto a elementos asociados al nivel de instrucción, los datos para estos barrios muestran diferencias. Para el caso de barrio Cristo Rey, en el año 2000 , el $84,5 \%$ de su población tenía estudios primarios y secundarios; no obstante, para el 2011 esta dinámica varió significativamente a $74 \%$ de su población; sin embargo, esta reducción en términos generales no puede ser valorada negativamente, dado que ello posiblemente revele procesos "naturales" de transición de estudios primarios a estudios secundarios, y de estos a educación superior u otros. En general, las cifras en 2011 reportan un aumento en casi todo los niveles de instrucción en términos relativos (INEC 2011); específicamente, en el año 2000 el $50.2 \%$ de su población contaba con estudios primarios completos, $33 \%$ secundaria y el $6,6 \%$ estudios superiores, pero para 2011, las personas con primaria completa representaban el $35 \%$ de la población, $40 \%$ en secundaria y universitaria $8,6 \%$; es decir, se reportó un aumento en casi todos los niveles de instrucción con excepción de primaria, donde se redujo en poco más del $10 \%$.
3. Del total de la población en barrio Cristo Rey, 2562 son hombres (\%) y 2724 son

mujeres para el caso de barrio Escalante, 356 son hombres $(39.2 \%)$ y 550 son mujeres $(60.8 \%)$.

4. Es oportuno subrayar que este estudio no se enfocó en el tema migrante como elemento sustantivo en términos analíticos a la hora indagar su objeto de estudio. Esto puede ser considerado una debilidad del estudio; sin embargo, traza la posibilidad de que trabajos futuros consideran esta dimensión como uno de sus núcleos centrales en relación con la convivencia urbana asociada con el intercambio del tiempo. En los casos que se analizan, se trabajó más desde las categorías de clase y género y su intersección. 
5. Es necesario destacar que cuando se mencionan actividades domésticas se alude al trabajo doméstico no remunerado. Tal como los feminismos lo han observado de forma crítica, es

fundamental visibilizar que el capitalismo contemporáneo es solo posible mediante esta labor subsumida y ocultada tras el ardid de la esfera privada y doméstica, que obedece a una lógica de división social sexual del trabajo, el cual le es impuesto a las mujeres para reproducir tanto al patriarcado como al capitalismo (Federici 2020, 254-256).
El caso de barrio Escalante, es la contra cara de barrio Cristo Rey. Para el año 2000, las personas habitantes de Escalante con educación superior y secundaria representaban el $44,5 \%$ y $25 \%$, respectivamente. En 2011 , la personas con educación superior y secundaria disminuyeron en un $7,8 \%$, y $32.1 \%$ correspondientemente y en relación con la educación primaria esta reducción fue de un 58\%; es decir, del 2000 al 2011 se pasó de tener 234 a 97 niños y niñas en primaria (INEC 2012, 2011a). Se evidencian procesos de despoblamiento, desplazamiento y sustitución del uso habitacional de Escalante.

Finalmente, en términos de empleabilidad, para el 2000, en barrio Cristo Rey un segmento importante de sus habitantes alrededor de un $29 \%$ se dedicaba al "comercio al por mayor y por menor", así como reparación de vehículos y efectos personales, etc.; además, se presentaba un importante grupo de habitantes ocupados en actividades de manufactura y maquila $(19.2 \%)$, lo cual puede ser interpretado como una tercerización y precarización de la actividad económica. Para el año 2011, el panorama de estas categorías y su importancia se mantuvo en términos relativos (INEC 2012, 2011a). En este punto, se puede señalar que barrio Cristo Rey sigue conservando su impronta popular y obrera característica de su origen histórico.

Con respecto a barrio Escalante, para el año 2000, se observó que la actividad inmobiliarias, empresariales y rentistas, así como el comerció representa las prácticas económicas principales para sus habitantes, $13 \%$ y $13,7 \%$, respectivamente. Para el año 2011, no hubo modificaciones significativas en esas categorías; no obstante, la enseñanza se convierte en la rama de actividad económica principal $(16,7 \%)$ seguida de actividades profesionales, científicas y técnicas $(13,2 \%)$ (INEC 2011).

\section{Breve reseña metodológica}

La investigación trazó, para su estudio empírico, partir de un paradigma que conjugara técnicas de estudio cualitativo (entrevistas semiestructuradas) y cuantitativo (encuesta). El ejercicio de indagación empírica estuvo siempre mediado por el ejercicio hermenéutico de interpretación teórico analítica que partió de enfoques críticos, los cuales ayudaron tanto a posibilitar la triangulación correspondiente como a problematizar el análisis.

Tanto las entrevistas cualitativas semiestructuradas como la encuesta se orientaron en función de seis niveles o dimensiones de estudio, que examinaron sus actividades y prácticas determinando ciclos y singularidad del ritmo de sus vidas cotidianas a lo largo de una semana entera -de domingo a sábado. Los niveles que se indagaron fueron a. la principal actividad laboral profesional, $b$. actividades domésticas ${ }^{5}, c$. desplazamientos y transporte, $d$. otras actividades (estudio, gestiones y compras, reparación y mantenimiento, cuidado de plantas y animales), e. ocio y tiempo libre y $\mathrm{d}$. actividades dirigidas a la comunidad. 
La muestra cualitativa estuvo conformada por un total de 12 de entrevistas (6 por barrio) con la siguiente distribución: dos personas jóvenes (15-35 años), dos personas adultas (36-65 años) y dos personas adultas mayores (65 o más años) ${ }^{6}$. La mitad mujeres la otra mitad hombres. Dichas entrevistas se efectuaron entre julio y noviembre del 2011.

En relación con los procesos cuantitativos, se entrevistó a informantes de 15 o más años que hayan vivido tres o más meses en ambos barrios. La encuesta se realizó durante octubre y noviembre del 2012. El tamaño de la encuesta fue de 123 personas para barrio Escalante y 180 para barrio Cristo Rey con un margen de error del $6 \%$ y un $90 \%$ de confianza. Es importante indicar que para el análisis de los datos tanto cualitativos como cuantitativos se utilizaron el Atlas-ti y el SPSS, respectivamente.

La descripción anterior es fundamental en aras de mantener presente el contenido de cada una de las actividades que se irán describiendo y analizando que, sin duda, se agolpan al saturar los resquicios del tiempo, que componen la vida cotidiana de cada una de las personas que realizaron y contribuyeron en el ejercicio de imaginar la "distribución" de sus actividades en una temporalidad para una división social y de género del tiempo cotidiano.

\section{Una reflexión sobre el tiempo desde N. Elias}

Sobre el tiempo, se podría decir que es un concepto que sintetiza un largo proceso humano de experiencias traspasadas de generación en generación; es decir, el tiempo era en el pasado un tema distinto de lo que es hoy, el tiempo cambió en el pasado y seguirá su mutabilidad en el futuro, entonces el tiempo -así como el espacio- no es como planteaban Descartes o Kant una síntesis "a priori", no es una capacidad innata de la razón sino una resultante del aprendizaje, la experiencia y de la capacidad de los seres humanos para transmitir esas experiencias y aprendizajes en forma de saber de generación en generación a través de los siglos (Elias 2013).

Esta tesis posibilita -como señala Elias (2013)- realizar un estudio de las transformaciones de la sociedades a partir de los cambios y las evoluciones de la temporalidades como síntesis conceptual y material (por ejemplo, las mediadas del tiempo según los ritmos productivos de la moderna economía tecnológica e industrial versus la medidas temporales dependientes de temporalidades naturales: fases lunares, cambios en estaciones, etc.); también, permite desmontar el problema del fetiche del tiempo como un objeto o sujeto, el tiempo "es una relación y no, como lo creyó Newton, un flujo objetivo" (Elias 2013, 65).

Al analizar estas reflexiones iniciales que comprenden al tiempo como una relación y un producto cultural de la actividad humana, en el devenir y con finalidades (lógica medios-fines), se puede acercar una definición al respecto.

De acuerdo con Elias, el tiempo es
6. Es importante comprender que la definición de los rangos de edad procuró brindar una visión temporal que lograra dar constancia de la memoria colectiva de las personas que habitan ambos barrio josefinos. 
7. Elias $(2013,94)$ define la síntesis como una facultad humana de imaginar como actual algo que no está y relacionado, con la verdad, que sucede aquí y ahora. La síntesis es decisiva en todas las formas en las que el tiempo es determinado. Así, no se podría decir que son las cuatro si antes no fueron las dos de la tarde; el antes y el después son demostración de la facultad humana para representar algo que no sucede en el mismo momento. el símbolo de una relación que un grupo humano (esto es, un grupo de seres vivos con la facultad biológica de acordarse y sintetizar ${ }^{7}$ ) establece entre dos o más procesos, de entre los cuales toma uno como cuadro de referencia o medida de los demás [...] Así pues, relacionar diversos procesos entre sí como "tiempo" significa al menos vincular tres entidades continuas: los hombres que relacionan, y dos o más entidades continuas en devenir de las cuales una cumple en cierto grupo humano con la función de continuum normalizado como marco de referencia para las demás $(2013,67-68)$.

Entonces, el tiempo es una relación sociohistórica, una condición de mediación entre las prácticas y actividades de los seres humanos que expresa y condensa el carácter político, económico y cultural de las relaciones de las personas y de esos grupos en una época particular (estadio civilizatorio; es decir, sus lógicas de organización (coacción-coerción). Por ello, Elias (2013) sostendrá que el tiempo no es solo una relación, sino una relación que se orienta por un fin y un sentido, una actividad que expresa una función entre sus tres entidades o polos:

esta la persona que, aquí y ahora establece y determinan las relaciones (determina el tiempo); está uno mismo como continuum en devenir entre el nacimiento y la muerte, sirviendo en este caso de continuum estandarizado, y está finalmente la multitud de procesos que uno mide con su propia vida, esto es, consigo mismo como continuum cambiante (Elias 2013, 68).

Sobre el poder de la "determinación de la temporalidad" se inscriben las experiencias, las prácticas y las voluntades de uso o intercambio temporales según las cualidades de las y los individuos, según el lugar en el espacio social donde deviene sus trayectorias socio biográficas (Wrigh-Mills 2006). Sobre ello, se ahondará en este trabajo, pero antes resulta necesario evaluar varias ideas más en relación con el tiempo. 


\section{Temporalidad e historia: el ritmo del capital o la lógica del intercambio}

Es necesario, entonces, subrayar que, como síntesis sociohistórica, el tiempo condensa en su lógica las formas políticas, económicas y culturales, que determinan y condicionan las pautas cotidianas de la vida social moderna en nuestra etapa civilizatoria. Esto quiere decir que el reloj biológico se regula y estructura, ya no tendencialmente por los ritmos metabólicos sino de acuerdo con los tiempos complejos que impone la organización social actual; en otras palabras, por la disciplina que imprime los ritmos cotidianos de la producción y la reproducción de una división social y de género del trabajo.

Lo anteriormente descrito no es otra cosa que una introducción a la vida cotidiana, pero habría que preguntar ¿es posible definir la vida cotidiana? Y siempre que se interroga sobre una definición, al respecto, emerge como punto de partida la premisa lefebvrerina que sostendrá que la vida cotidiana es la realidad suprema. En ella desemboca y se conjuran toda la potencia, la virtuosidad y el drama de lo humano; por ello, el núcleo real de la acción -praxis- al tiempo que la creación: poiesis. La vida cotidiana es el lugar por excelencia donde la humanidad despliega su segunda naturaleza, donde dibuja un orden social el cual crean y recrea incesantemente, casi de forma inconsciente sin detenerse a pensar en las fuerzas o poderes ocultos que lo organizan y le donan (sin) sentido (Kosík 1967, Lefebvre 1972).

La vida cotidiana es, por tanto, la película originaria, el escenario real donde producimos el mundo con su vida urbana, suburbana o pueblerina, con su arte, cultura e instituciones. Es el pasaje de los ritos, las agencias y las actuaciones; el escenario, entonces, del flâneur banjaminiano por entre la escenografía citadina. Por ello, es tráfico y tránsito de nuestras existencia en sus decadencias, bajezas, afectos, emociones, deseos es la vida y la muerte; se presenta como el escenario donde todo acontece, la "banalidad" de la inmediatez o el término desde donde lo particular singular ${ }^{8}$ sostiene y origina los acontecimientos que trascienden lo cotidiano ${ }^{9}$; quizás, el curso más fino para comprender lo trascendental en la historia relatada por los triunfadores; por lo anterior, la vida cotidiana sintetiza y ensambla vigorosamente el lugar de la producción de la vida humana tanto material como simbólicamente es el momento de la re-producción, por ende, de las repeticiones, rutinas, rotaciones, ciclos desde y donde se organiza el tiempo bajo el imperio de las lógicas de la sociedad patriarca y capitalistas contemporánea (Kosik 1967, Lefebvre 1972, Lefebvre 2006).

En síntesis, la vida cotidiana es -como sostiene Agnes Heller- "el conjunto de actividades que caracterizan la reproducción de hombres y mujeres particulares, los cuales crean la posibilidad de la reproducción social" (2002, 37). Ese sistema de actividades de producción y reproducción condensa un orden, una suerte de arquitectura del tiempo cotidiano.
8. O donde concurre la vida de las personas anónimas sumidas en la pesada normalidad impuesta, vidas ignoradas y ocultas entre la multitud.

9. Por ello, el germen de lo extraordinario que irrumpe fracturando o suspendiendo lo ordinario, hablamos, por ejemplo, de las guerras, también de la fiesta, etc. 
10. Es importante destacar que, tanto teórica como metodológicamente los estudios sobre el uso del tiempo invisibilizan en mayor o menor grado, la lógicas de intercambio que determinan y condicionan justamente las posibilidades del gobierno sobre la temporalidad. La ausencia de la relación entre intercambio y uso es un error tanto teórico como técnicometodológico (Durán y Rogero 2009, Durán 2006 y Page 1996).
Esa arquitectura temporal es hoy el tiempo del modo de (re)producción capitalista (y sus formaciones), su organización, lógica, función, simetría y valor es determinado tendencialmente por las fuerzas de las actividades y prácticas del campo de la economía -el mercado en su ideológica libertad. El tiempo, el reloj como objeto físico que materializa la relación temporal, es medida de valor que posibilita que la fuerza de trabajo físico e intelectual de los sujetos sea una mercancía más dispuesta para el intercambio y el uso para el cuido y la reproducción en la vida del hogar para la compra y la venta en el mundo del trabajo productivo. El reloj como objeto material, así como el calendario, desplaza y sustituye la duración filosófica. Lefebvre (2006) expresa con belleza la representación e importancia del reloj en la era del capital que acá se explica:

muestra desde a fuera el tiempo vivido y lo ordena $[\ldots]$ no se contenta con representar el tiempo; eleva la mediación del tiempo vivido a la mediación social. No hace más que simular los ritmos cíclicos de la vivencia, simulación obtenida por la esfera y la vuelta de la esfera, por las doce horas divididas en doce veces cinco minutos pero también por el tic-tac que simula los latidos del corazón. Subordina el tiempo cíclico al tiempo social [...] Con ello preside; no sólo reina sobre el tiempo de trabajo sino sobre la totalidad de las coacciones y obligaciones sociales. El reloj permitió la producción y el salario generalizado; también permitió el pleno desarrollo del capitalismo con su adagio: "El tiempo es oro (38).

El tiempo, como síntesis de la sociedad culturalmente burguesa y patriarcal productivamente (neo) capitalista liberal, es una relación social que resguarda una "lógica" de intercambio más que una determinación de uso-utilidad. El uso del tiempo está subordinado a la hegemonía del intercambio. El atributo central de la temporalidad moderna es ser cuantificable no ser calificable. El calendario, el mes, la semana, el día, la hora, minutos, entre otros ... se condensa en el reloj expresión material objetiva-tecnología, que permite medir y sustituir la actividad del trabajo en un salario equivalente que puede resumirse en la fórmula: trabajo-tiempo/reloj-dinero ${ }^{10}$.

Lefebvre (2006) señalaba que justo esta operación, como representación ideológica de una realidad excluyente y desigual, no solo ayuda a disimular el plusvalor que extrae el capitalista del trabajo de los obreros sino que legiti- 
ma, a su paso, un estado de cosas, un orden social y económico y cultural, habría que agregar que la operación trabajo-tiempo-dinero salario ${ }^{11}$ no solo indicaría el plusvalor sustraído, sino también el tiempo excedente del que disfrutan ciertos grupos y clases del tiempo sustraído de otras personas y clases subordinadas.

La cantidad de tiempo de ocio, y en especial la posibilidad (voluntad de poder) de su uso, esto es, las vivencias, las experiencias de este, revelarán la diferencia cultural y la desigualdad social que disimula y oculta la operación trabajo-tiempo-dinero al volver transparente la calidad en la cantidad del tiempo del que disponen las y los individuos, develará la autonomía y la voluntad de poder sobre el tiempo a partir de lugar social, la clase, también, el género, en la que se despliega las biografía las personas.

Como ya fue mencionado, estudiar el tiempo al partir del axioma del valor útil -valor de uso- del tiempo en lugar del valor de cambio-intercambio supone paradójicamente una representación ideológica de la realidad social desigual y excluyente que busca representar. Lo que se apunta es que, en el mejor de los casos, es preciso partir de la necesaria articulación y la tensión dialéctica entre el par analítico clase-género, que buscaría librar aquellas perspectivas que escinden un "trabajo" para el mercado y un "trabajo no para el mercado" cuando la lógica de intercambio tal como sostiene Lefebvre (2006) se presenta totalitaria; es decir, se dispone a organizar y estructurar al condicionar la temporalidad diaria de las actividades sustantivas de las y los seres humanos en una arquitectura básica dispuesta en tiempo productivo o de trabajo, tiempo de trabajo reproductivo o el tiempo de la vida doméstica y el tiempo de fuga o residual: tiempo de ocio. Todas estas temporalidades profundamente articuladas.

Habría que decir, necesariamente, que ese tiempo reproductivo, que alude a la vida doméstica, como su escenificación concreta, podría considerarse como la base desde donde se constituye tanto el tiempo productivo como el tiempo de ocio en el capitalismo; entonces, lleva razón Federici (2020) cuando anuncia que la crítica lefebvreriana sobre el tiempo, el espacio y la vida cotidiana solo se completa y agudiza cuando la crítica feminista entiende que la vida doméstica es el núcleo espacio-temporal del trabajo no remunerado y, por ello, el arché donde se constituyen la reproducción social de las principales relaciones de dominación y sobreexplotación en el capitalismo ${ }^{12}$.

12. Sugiere, por tanto, que la economía de los cuidados esta subsumida por la economía

Las mismas relaciones se originan en una división sexual del trabajo acompañado de una división sexual del tiempo social que convierte a la mujer en el sujeto fundamental de todo lo ominoso y objeto de subordinación por excelencia para la producción ampliada de la sociedad capitalista patriarcal contemporánea. Lo anterior permite, entonces, trascender posiciones individualista psicologizantes, propio de ciertas ciencias sociales, que fragmenta las política del capital, la cual la instrumentaliza en función de la ganancia y reproduce a su paso relaciones de dominación y sobreexplotación fundamentadas en el patriarcado y lo perpetua. experiencias y separa lo mental de su dimensión sociocultural, así como una 
13. La potencia, la lógica y la finalidad de esta arquitectura temporal fueron descritas y definidas teórica y analíticamente en la sección anterior; por tanto, es subyacente y orienta toda la discusión. ruptura epistemológica con la tendencia de partir de sujetos abstractos ocultos bajo falsos universalismo asexuados (Federici 2020, 252-253)

Ahora bien, tomando en cuenta lo planteado por Federici (2020), el estudio del tiempo debe estar centrado en la relación intercambio-uso-intercambio y no en la categoría de uso; se sostendrá que, partir del uso sin más, termina por disimular y legitimar la contradicción constitutiva de la relación capital-trabajo, la cual oprime, en especial, a las mujeres, contradicción o contradicciones que la sociedad costarricense no estaría liberada. Desplegada la reflexión teórica que sustenta este manuscrito, se procederá a la exposición de los resultados.

\section{Sobre el intercambios y los usos del tiempo en barrio Escalante}

En términos generales, lo primero que habría que establecer para ambos espacios barriales es que el tiempo social lo absorben tres grandes actividades prácticas. Ellas son las tareas ligadas a las esferas del trabajo, la vida doméstica y el ocio. Se podría sostener que estas son las prácticas sustantivas que constituyen el tejido de la vida cotidiana en ambos barriales. A esta estructura, como ya se anunció, se le denominó como arquitectura de la vida cotidiana $^{13}$.

El tiempo medio en estas tres esferas ofrecen detalles reveladores, si se mira desde la clave del género. En principio, y al partir de las mujeres que habitan barrio Escalante, este grupo intercambia 45 horas de su tiempo social percibido en labores remuneradas ligadas al mundo del trabajo. De este total, el grueso del tiempo se consume de lunes a viernes con un total de 33.8 horas. El fin de semana las habitantes de barrio Escalante disponen 5,7 horas y 6 horas, respectivamente, de su tiempo para el trabajo.

Por su parte, los habitantes de barrio Escalante intercambian, en términos medios, un aproximado de 39 horas de su tiempo entre semana, los días sábados y domingos, en promedio, dedican 5,8 horas tareas relacionadas con actividades laborales; es decir, en total los hombres, en barrio Escalante, intercambian 50,6 horas de su tiempo social a actividades vinculados al mundo del trabajo. Claramente, el dato indica que los hombres trabajan 5,6 horas más que las mujeres por semana; sin embargo, si se toma el tiempo laborado absoluto en términos relativos se encuentra que, los hombres intercambian un $22,8 \%$ del mismo en tanto las mujeres un $22,7 \%$ de su tiempo. La diferencia es tan solo ahora de $0.1 \%$, por lo que, se puede sostener que hay una igualdad en términos del tiempo dispuesto para actividades de orden laboral para ambos grupos según su género.

Ahora bien, al trasladarse a la esfera de la vida doméstica, tanto para las mujeres como para los hombres de barrio Escalante las actividades relacionadas con la vida cotidiana del hogar absorben mayor cantidad de su tiempo social. Para el caso de las mujeres, las actividades no remuneradas repre- 
senta un 77, 2 horas por semana. Estas se distribuyen en 41,5 horas de lunes a viernes y los fines de semana estas llegan casi a igualar el trabajo doméstico realizado entre semana al alcanzar 35,7 horas (ver cuadro 1 ).

\begin{tabular}{|c|c|c|}
\hline \multicolumn{3}{|c|}{$\begin{array}{l}\text { Cuadro 1. Intercambio y uso del tiempo percibido por habitantes d } \\
\text { barrio Escalante }\end{array}$} \\
\hline Espacialidad temporal & Hombres & Mujeres \\
\hline Tiempo de trabajo & 50,6 horas & 45 horas \\
\hline Tiempo doméstico & 102,2 horas & 77,2 horas \\
\hline Tiempo libre/Ocio & 19,5 horas & 19 horas \\
\hline
\end{tabular}

Fuente: Encuesta convivencia urbana 2014.

Sin embargo, en el caso de los hombres, el tiempo social orientado a actividades de orden doméstico representa 102,3 horas de su tiempo social percibido. Lo anterior traza un "hallazgo" controvertido: el desplazamiento relativo de los roles de género en la esfera doméstica; es decir, en el caso específico de barrio Escalante, los hombres presenta tiempos medios más elevados que las mujeres en algunas actividades de "naturaleza" doméstica. En principio, se podría sostener que los habitantes de barrio Escalante establecen relaciones de género, que tendencialmente marcan una ruptura con patrones culturales hegemónicos de la masculinidad convencional de carácter patriarcal; tal situación se podría sostener a partir del comportamiento "casi" igualitario en actividades tales como alimentación y cuido de otras personas.

Sin embargo, al someter estos datos al análisis profundo y detallado de las tasas de respuesta, sí o no, en la participación de las actividades que organizan la división social del tiempo y se observan esas respuestas bajo el criterio del género, se encuentra que esa "realidad" se empieza a desvanecer.

Cuando se miraban actividades tales como el cuido de personas, se denota con asombro que los hombres le dedican muchas más horas a estas labores no remuneradas, que a labores productivas propias de la esfera del trabajo; no obstante, al revisar las respuestas afirmativas y negativas, se encontró que tan solo el $15 \%$ de los hombres entrevistados se abocan a tareas relacionadas con el cuido de personas contra $26,6 \%$ de mujeres. La diferencia significativa del cuido entre hombres y mujeres empieza a difuminarse cuando se observa que una de cada cuatro mujeres, que habitan barrio Escalante, realizan este tipo de actividades con respecto a los hombres, cuya probabilidad es de aproximadamente una de cada seis.

Otro ejemplo, al prestar atención otra vez a las respuestas "sí" frente a la respuesta "no" asociadas a las actividades domésticas de limpieza, se encuentra que el $56,3 \%$ sostiene realizar labores no remunerado de limpieza del ho- 
14. El tiempo que se pierde en transporte público o privado (tren, buses, taxis, bicicletas, vehículo particular, etc.) o caminando entre las calles y avenidas (parques, bulevares entre otro) del barrio y la ciudad al enfrentar la contaminación sónica, la contaminación ambiental, los congestionamientos vehiculares. gar frente a un $43,4 \%$, que reportan dedicar tiempo a este tipo de actividades de orden reproductivo. Un tercer ejemplo, que demuestra la aparente transformación de la equidad de género en el barrio, se da cuando se presta atención a la realización de las tareas de alimentación y limpieza. Las mujeres llevan, como es tradicional y esperable en una sociedad capitalista patriarcal, el peso de su realización con un $51 \%$ y $61 \%$, respectivamente, frente a los hombres con un $48 \%$ y $39 \%$, respectivamente.

Además del ejemplo ya citado, cuando se analiza otra actividad como las de mantenimiento y la reparación de la vivienda, esta se comporta de manera normal en términos de la división sexual patriarcal del trabajo en el hogar. ¿Qué quiere decir esto? Un $69 \%$ de los hombres de Escalante reporta dedicar su tiempo a estas actividades, en tanto solo $30 \%$ de las mujeres dispone de tiempo para el mantenimiento de sus viviendas.

El comportamiento de los datos parece plantear, en términos teóricos, una suerte de sesgo machista-sexista en las respuesta dada por los hombres de Escalante, que genera un inflación en los valores asignados por ellos a los tiempos percibidos que usan en las tareas no remuneradas propias de la vida en el hogar. En ese sentido, resulta que se termina por conformar y estilizar una aparente realidad de igualdad de género que, como ha sido demostrado, no se corresponde con la realidad que se encuentra con el análisis profundo de esos mismos datos. Dicha situación es corroborada por la prueba cualitativa, tal como se verá más adelante en este artículo.

Ahora bien, en cuanto al comportamiento del ocio (entretenimiento, recreación, etc.), la encuesta señaló que las habitantes de Escalante orientan 12.1 horas de lunes a viernes a este tipo de actividades y 3,3 horas, los días sábados y 3,7 horas, los domingos. La sumatoria de tiempo social dedicado al ocio y la recreación supone un total de 19,2 horas a la semana. El caso de los habitantes hombres de Escalante, se comportó de manera semejante entre semana 11 horas y los fines de semana 8,4 horas para un total de 19,4 horas a la semana. Para dimensionar el peso y lugar del ocio en el tiempo social de las personas de este barrio, es necesario situarlo en perspectiva con el trabajo y el tiempo que se fuga en actividades de desplazamiento y recorridos por la ciudad.

La relación ocio-trabajo se presenta de esta manera. En el caso de las mujeres, el tiempo dedicado a actividades laborales representa, solo los fines de semana (temporalidad que desde el conocimiento común está dispuesto para el descanso), 11,7 horas y para el caso de los hombres, la media es 11,6 horas. Ahora bien, si fija la atención en la media de tiempo dispuesto para el recorrido y el desplazamientos ${ }^{14}$, de los habitantes del barrio Escalante, los habitantes del barrio Escalante invierten un total de 21,8 horas y 22,7 horas, respectivamente, en recorridos y desplazamientos por semana; en otras palabras, en ambos casos, el tiempo en actividades de desplazamiento y transporte sobre pasa casi por tres horas al tiempo que los habitantes de Escalan- 
te dedican a actividades de orden recreativo y lúdicas. Este panorama descrito por el dato, tan solo subraya que el ocio se presenta a manera de una experiencia de caracter extraordinario incluso ahí, donde supone el sentido común dicta que es el lugar "natural" de su despliegue y posibilidad.

\section{Sobre los intercambio y usos del tiempo en barrio Cristo Rey}

La división social del tiempo cotidiano de los habitantes de barrio Cristo Rey encuentra similitudes y distancias con respecto a barrio Escalante. De inicio, se puede subrayar que, para ambos espacios barriales, el ritmo temporal de la vida cotidiana está siendo determinado por dos actividades sustanciales, que pueden ser definidas como las tareas propias del mundo de la vida doméstica y el mundo del trabajo.

Al partir de esa característica central estructural y en relación con las mujeres habitantes de barrio Cristo Rey, la media de tiempo que intercambian las habitantes del barrio en el mercado laboral es de poco más de 37 horas de lunes a viernes y para los fines de semana asignan 7,8 horas los sábados y 8,13 horas los domingos. La sumatoria para toda la semana es de 53,2 horas vinculadas a actividades asociadas con el trabajo asalariado; en términos relativos, un $22,2 \%$ del tiempo social cotidiano percibido es dedicado al trabajo durante una semana ordinaria.

Para el caso de los hombres de barrio Cristo Rey, el tiempo medio sustraído por el trabajo es de 42,1 horas de lunes a viernes; para los fines de semana, intercambian 8,5 horas los sábados y 8,4 horas los domingos; en suma, 59 horas a la semana es el tiempo total dedicado a la esfera del trabajo.

Los datos son claros en señalar que a los hombres, quienes viven en este barrio popular, el mundo del trabajo, les sustrae 6 horas más que a las mujeres del mismo barrio. Es relevante subrayar que, para los habitantes de barrio Cristo Rey, el trabajo se presenta cuantitativamente como la actividad determinante que pauta el ritmo y la lógica del continuum de su tiempo social cotidiano. Este fenómeno es único para este segmento de población particular de la muestra, dado que, para el caso de las mujeres de barrio Cristo Rey como para las mujeres y hombres de barrio Escalante, la vida doméstica se despliega como la actividad que condensa en términos cuantitativos la mayor demanda de su tiempo (ver cuadro 2).

Al pasar a la esfera de la vida doméstica, y como ya es evidente, las actividades asociadas al hogar constituyen el segundo pilar de la organización sociotemporal en ambos barrios. Para las mujeres de barrio Cristo Rey, al igual que sus pares de barrio Escalante, el cuido es la tarea que más tiempo les absorbe entre semana. El cuido de otras personas demanda 31,3 horas de lunes a viernes y 8,8 horas, los días sábados y 9,8 horas, los domingos. 
15. El tiempo percibido se refiere a la duración temporal que las personas perciben como invertidas en las diferentes dimensiones $y$ actividades cotidianas.
16. Las personas, quienes habitan barrio Escalante, gastan 44, 6 horas a la semana en desplazamientos ( 21 horas para las mujeres y 22 horas para los hombres). Para los habitantes de barrio Cristo Rey, el consumo se dispara a 71,4 ; solo los hombres gastan 43 horas casi todo el tiempo que disponen los habitantes de barrio Escalante. En total, toda la población estudiada pierde 116 horas de la semana en traslados al moverse entre las calles, las avenidas, las aceras, los bulevares y los parques, en sus barrios, en la ciudad de San José.

\section{Cuadro 2. Intercambio y uso del tiempo percibido por habitantes de barrio Cristo Rey}

\begin{tabular}{lcc}
\hline Espacialidad temporal & Hombres & Mujeres \\
\hline Tiempo de trabajo & 59 horas & 53,2 horas \\
Tiempo doméstico & 91 horas & 103 horas \\
Tiempo libre/Ocio & 17,5 horas & 16,6 horas \\
\hline
\end{tabular}

Fuente: Encuesta convivencia urbana 2014.

Para el caso de los habitantes de barrio Cristo Rey, y a diferencia de sus congéneres de barrio Escalante, no cabe duda de que la división social del tiempo cotidiano por género expresa claramente la lógica de dominación masculina-patriarcal. La vida doméstica consume un $53 \%$ del tiempo percibido ${ }^{15}$ por los hombres en una semana. Las principales actividades en las que usan el tiempo relacionado con el ámbito de la vida doméstico son las siguientes: el cuido de otras personas, las tareas relacionadas con el mantenimiento de la vivienda que les demanda un total 14,1 horas y tareas de alimentación, lo cual les absorbe 5,7 horas de temporalidad durante la semana.

Siguiendo la lógica expositiva del presente trabajo, el ocio para las habitantes mujeres de barrio Cristo Rey representa casi 16,5 horas por semana y para el caso de los hombres el tiempo "libre" significa una media de 17,5 horas. En otras palabras, el tiempo de ocio para las mujeres y los hombres de Cristo Rey representa poco más de $8 \%$ ( $8.2 \%$ y $8.3 \%$, respectivamente) de su tiempo social percibido. El ocio vuelve a presentarse como un tiempo escaso en la vida cotidiana de las personas habitantes de la ciudad de San José.

Inclusive, tanto las mujeres como los hombres que viven en este barrio del sur pierden más tiempo en actividades de desplazamiento, ya sea caminando, en vehículo propio u otro tipo de transporte. Por ejemplo, los hombres utilizan 43 horas media por semana en desplazamiento; para el caso de las mujeres, usan poco más de 28 horas desplazándose por el barrio o la ciudad.

Se vuelven a encontrar elementos preocupantes; por ejemplo, la dinámica de desplazamientos y ocio, donde el tiempo consumido por las mujeres de barrio Cristo Rey caminando o bien movilizándose, en transporte privado o público, supera (y por mucho) el tiempo que disponen en actividades dedicadas al ocio o la recreación ${ }^{16}$. El panorama se vuelve más agobiante cuando los desplazamientos se articulan con las horas de trabajo semanales (53 horas), el trabajo doméstico (103 horas) y las tareas relacionadas con educación (18 horas). Estas tareas representan en términos relativos un $84.9 \%$ del tiempo cotidiano, que perciben tener las mujeres de barrio Cristo Rey.

En términos generales, el análisis del intercambio y el uso del tiempo en cada uno de los espacios barriales encuentra como uno de sus principales hallaz- 
gos que la condición de clase social y género son categorías que ayudan a comprender la dialéctica del tiempo; es decir, son el lugar donde se conjugan las semejanzas y la síntesis estructural del tiempo social cotidiano: organización del continuum ritmo del tiempo cotidiano, de su ciclo por la determinaciones del mundo del trabajo capitalista (clase) y los determinantes reproductivos de la vida doméstica (género). Asimismo, entre estos dos universos o esferas temporales vitales emergen y existe el tiempo de ocio, el cual se presenta como una temporalidad residual.

Esta arquitectura dibuja la pauta homogénea o una suerte de realidad unidimensional, que es común a ambos espacios barriales citadinos; es decir, la diferencia transita por la intersección clase-género ${ }^{17}$. En cada uno de las dimensiones ya revisadas: el tiempo de trabajo, el tiempo doméstico no remunerado y el tiempo de ocio revelan que las temporalidades intercambiadas, consumidas y usadas en términos cuantitativos representan cantidades diferenciadas.

En relación con el género, las mujeres de barrio Cristo Rey superan a todo la población en estudio (hombres y mujeres de ambos espacios urbanos) en relación con las horas consumidas en tareas no remuneradas. Es notorio que las cifras son claras. Al respecto, las mujeres de barrio Cristo Rey invierten 25 horas más en actividades domésticas que las habitantes barrio Escalante y en relación con los hombres de su mismo barrio por encima de las 12 horas. Estos datos son indicadores de la presencia de una temporalidad condicionada por el género al reafirmar lo ya señalado: la vida doméstica es una temporalidad con rostro de mujer.

\section{Cuadro 3. Intercambio y uso del tiempo percibido por habitantes de barrio Cristo Rey y barrio Escalante}

\begin{tabular}{lcccc}
\hline \multirow{2}{*}{$\begin{array}{l}\text { Espacialidad } \\
\text { temporal }\end{array}$} & \multicolumn{2}{c}{ Barrio Escalante } & \multicolumn{2}{c}{ Barrio Cristo Rey } \\
\cline { 2 - 5 } & Hombres & Mujeres & Hombres & Mujeres \\
\hline $\begin{array}{l}\text { Tiempo de } \\
\text { trabajo }\end{array}$ & 50,6 horas & 45 horas & 59 horas & 53,2 horas \\
$\begin{array}{l}\text { Tiempo } \\
\text { doméstico }\end{array}$ & 102,2 horas & 77,2 horas & 91 horas & 103 horas \\
$\begin{array}{l}\text { Tiempo libre/ } \\
\text { Ocio }\end{array}$ & 19,5 horas & 19 horas & 17,5 horas & 16,6 horas \\
\hline
\end{tabular}

Fuente: Encuesta convivencia urbana 2014.

El trabajo devela otro lugar en donde la undimensionalidad estructural del tiempo resguarda una distinción; tanto los hombres y las mujeres de barrio Cristo Rey superan notoriamente en el tiempo social medio percibido que in-
17. El concepto de interseccionalidad es una herramienta analítica que posibilita visibilizar identidades y relaciones múltiples en ensamble problemático sociohistórico, que develan la operación y la acción de estructuras de poder por tanto de opresión y dominación en función, al menos, de la clase, el género y la raza-etnia (Días y Torrado 2019). Es un concepto que procede del feminismo negro, mayormente. 
18. Se presenta un aproximado de salario por barrio, pero estas medias de salarios hay que comedirlas con otras variables tales como la edad, el nivel educativo, los grupos laborales y la rama de actividad, que son significativas en tanto los dos barrios son distintos en la composición sociodemográfica. Los datos sobre el salario fueron extraídos de la encuestad de convivencia urbana.

19. En la descripción demográfica de ambos espacios se demostró cómo el tema educativo es clave para comprender el acceso a mejores trabajos y empleos. tercambian en el mercado de trabajo en relación con los habitantes de barrio Escalante. Tan solo las mujeres de Cristo Rey superan en 8 horas y 3 horas, respectivamente, a las mujeres y los hombres de barrio Escalante. Para el caso de los habitantes de barrio Cristo Rey, la brecha es superlativa. Excede en 14 horas de trabajo a las mujeres de barrio Escalante y a sus pares masculinos en casi 9 horas más de trabajo (en términos reales una jornada adicional completa).

Si anteriormente se sostuvo que el tiempo social contiene una coerción de género sobre la organización del tiempo, se puede aseverar desde la misma prueba empírica cuantitativa la existencia de una división social tiempo que obedece a condicionamientos vinculados a la clase social para las personas, que habitan ambos espacios barriales.

Esto solo confirma que la arquitectura del tiempo analizada, se constituye bajo una razón económica de carácter capitalista, la cual sutilmente se ensamblan con una impronta cultural patriarcal, las cuales, en conjunto, resultan en una división social y sexual del trabajo; es decir, tal como ilumina el concepto de interseccionalidad, estamos ante la presencia de una arquitectura temporal, que revela e indica un sistema complejo de estructuras temporales de opresión múltiples y simultaneas (Díaz y Torrado 2019), que funciona de modo restrictivo y con especial énfasis para las personas que viven en barrio Cristo Rey.

Ahora bien, si se mira cómo se construye la diferenciación social entre los barrios, al conjugar las variables de género-trabajo y salario, se encuentra con total claridad como la operación trabajo-tiempo-dinero, que constituye la arquitectura unidimensional del tiempo y vuelve a mostrar distinciones. La retribución media salarial que reciben los habitantes por la venta de su tiempo es para las mujeres y los hombres de barrio Escalante de $\$ 486032$ colones y ф726 743 colones respectivamente, frente a una media de $\phi 301900$ y $\phi 371$ 130 para las mujeres de y hombres que viven en Cristo Rey, respectivamen$t^{18}$. La desigualdad social ya no solo se expresa en el tiempo excedente que les es sustraído a las personas que habitan barrio Cristo Rey, sino que hay una distribución desigual de salario por la compra del tiempo en el mercado de trabajo.

En términos relativos, las mujeres en barrio Escalante ganan 38,8\% más dinero que sus congéneres de Cristo Rey. Los hombres de barrio Escalante reciben un $48,9 \%$ más de dinero que los trabajadores de barrio Cristo Rey. En otra perspectiva, las mujeres de barrio Escalante reciben un ingreso que supera en $23,6 \%$ el ingreso medio de los hombres de barrio Cristo Rey y los hombres de barrio Escalante perciben un ingreso 58,4\% mayor que el de las habitantes de Cristo Rey ${ }^{19}$.

La relación de tiempo y trabajo-remuneración salarial indica que, en barrio Cristo Rey, las mujeres y los hombres trabajadores laboran en promedio 8,8 
horas y 9,8 horas por día y perciben salarios $38,8 \%$ y $48,9 \%$ menores que sus pares de barrio Escalante. Básicamente, en términos de clase, los habitantes de barrio Cristo Rey trabajan más tiempo por menos dinero y en clave de género, en este escenario, las mujeres quedan justo en intersección entre el género y la clase social.

La discusión y reflexión, en torno al ocio, nos posiciona estratégicamente en las puertas de otra semejanza analítica, en lo que se puede denominar la asfixia del ocio. Pero, para comprender y explicar esta alegoría, es necesario comprender el peso y tensión que imponen y ejercen el ritmo productivo del mundo cotidiano del trabajo y el ritmo de reproducción del mundo de la vida cotidiana.

En términos generales, el ocio se presenta como un parodia del tiempo libre. Opera como la temporalidad donde se presupone que no se "despliega" ninguna actividad relacionada temporalmente con el trabajo; sin embargo, la metáfora de la asfixia del tiempo del ocio no se constituye tan solo por la acción del ritmo de producción del tiempo del mundo del trabajo capitalista, sino también por la presión que se ejerce desde la vida doméstica y su ritmo de reproducción, la vida doméstica y las labores no remuneradas que requiere. Se muestra, entonces, cómo el segundo pilar que soporta la arquitectura temporal del mundo de la vida cotidiana y que supone un espacio específico, el del mundo de la vida "privada": la intimidad del hogar.

Solo así es posible entender cómo el ocio representa, en término relativos, $8,3 \%$ y el $9,6 \%$ del tiempo percibido total para para las mujeres y los hombres habitantes de Barrio Escalante o el 7,1\% y $6,7 \%$ en las mujeres y hombres que viven en Barrio Cristo Rey y cómo las actividades relacionadas con el mundo de cotidiano de la vida doméstica consumen el 39\% del tiempo percibido para Cristo Rey en el caso de Escalante que absorbe el 41,4\%. El tiempo que gozan las personas para el ocio se restringe por la necesidad de las personas para preparar alimentos, cuido de personas, limpieza y mantenimiento de las viviendas, compra de alimentos, pagos de servicios, estudio, etc.

Pero, la desigualdad y las diferencias sociales, entre los barrios, se denota, también, en relación con el ocio, tal como sostendría Baudrillard (1970, 222): "El ocio, repartido desigualmente, sigue siendo, en nuestras sociedades democráticas, una factor de selección y distinción cultural"; sin embargo, el ocio (fin de la jornada de trabajo o las vacaciones) prepara el trabajo así como el trabajo prepara el ocio. El ocio esta pletórico de actividades (consumo, entretenimiento, etc.) que se asemejan al mundo del trabajo, donde sino en el tiempo de ocio se acomoda a las praxis del consumo masivo de la sociedad contemporánea (Marcuse 1968, Baudrillard 1970, Baudrillard 1974; Lefebvre 2006, y Jameson 1995). 
Ilustración 1. Arquitectura temporal del mundo de la vida cotidiana

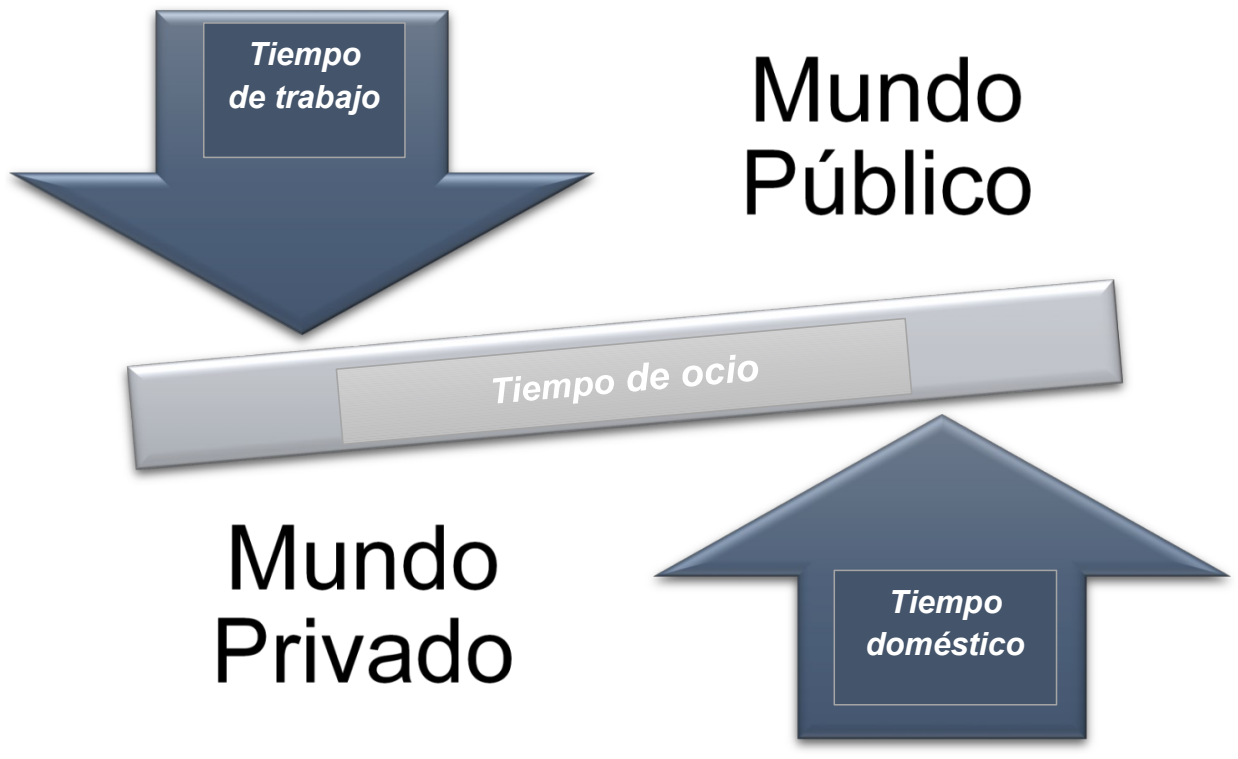

Fuente: Elaboración a partir de la Encuesta de Convivencia Urbana (Solís y Coto 2013).

Al volver, de nuevo, la mirada a los espacios urbanos que nos ocupan, el tiempo adquirido para el ocio y la recreación indica, primero, una desigualdad enunciada en el acceso al bien tiempo de ocio traducido como actividades de recreación. Los hombres y las mujeres de barrio Escalante gozan de mayor tiempo de ocio que las personas que viven en Cristo Rey; los hombres (19,5 horas) y las mujeres (19,3 horas) de Escalante acceden a dos horas más de tiempo de ocio que sus contrapartes de barrio Cristo Rey; así, la ociosidad funciona como un signo de distinción de clase, donde el mayor tiempo dedicado a actividades de entretenimiento, recreación o cuido personal y moral se cristaliza como un signo de mayor estatus entre los barrios como apuntaba Baudrillard (1974).

Sin embargo, para comprender a profundidad las diferencias sociales y culturales entre los barrios en estudio, lo que emerge como necesidad analítica es captar el detalle del significado de la vivencia del tiempo, en general, del tiempo de trabajo, del tiempo de la vida doméstica y el ocio por parte de las personas que habitan estos céntricos barrios josefinos es oportuno y necesario ir al sentido de la experiencia material cotidiana. Esto es a la caracterización cualitativa de la vida cotidiana o de como el tiempo como símbolo de una relación entre grupos o clases de personas establecen las distinciones en la vivencias de esta arquitectura temporal productivista de lógica capitalista como proceso hegemónico (Elias 2013). 


\section{Entre la autonomía del tiempo y la rutina del trabajo}

Richard Sennet (2004) en su obra "La corrosión del carácter" planteaba la tesis de que las sociedades del capitalismo benefactor e industrial presentaban una organización temporal rutinaria y disciplinaria. Ello era expresión de tejidos sociales que potenciaban trayectos individuales en donde la relación trabajo-profesión eran parte constitutiva del carácter e identidad de las y los individuos; no obstante, con el advenimiento del capitalismo tardío o neocapitalismo, la rutina y la disciplina asociadas a las temporalidades burocráticas del Estado se lo opuso un tiempo nuevo productivo, que subraya el valor de la flexibilidad por sobre la rutina. El tiempo flexible, emerge como una respuesta y ruptura frente a la jaula de hierro de la razón instrumental burocratizante de ese viejo capitalismo benefactor localizado (Weber 2015).

Traer a colación este diagnóstico no es arbitrario, dado que es coincidente en muchos puntos con otros diagnósticos en relación con el ambiente cultural y social de los tiempos actuales, los cuales señalarían que el individuo de la modernidad contemporánea se despliega cotidianamente en un tejido social (espacio-tiempo), donde sus seguridad ontológicas se apoyan sobre un suelo frágil o bien líquido (Bauman 2006) o una superficie en el que las nuevas normas sociales, las coordenadas de convivencia social, no se han terminado de solidificar cuando de apoco se desvanecen en el aire (Marx 1974, Berman 1989).

Esta diagnosis de la actual modernidad capitalista, se podría sostener que está presente tanto en barrio Cristo Rey como en barrio Escalante, de manera concreta en el mundo del trabajo y el ocio. En ambos escenarios barriales, se expresa de una parte la flexibilidad temporal "posmoderna" pero, a su vez, la persistencia en el tiempo del "anacrónico" y "seguro" ritmo rutinario condorceano (Sennet 2004).

La exposición de estos fenómenos sociales ilustra aún más profundamente las diferencias y el antagonismo de clase-género en relación con la vivencia material del tiempo y además nos indican que la sociedad costarricense moderna se encuentra transitando entre estos estados culturales temporales evanescentes; es decir, tal y como lo señalaba Elias (2013) en nuestro presente encontramos en el tiempo, sintetizadas experiencias temporales diferenciadas que indican una colisión entre formas rutinarias y formas flexibles que están en una relación dialéctica.

\section{Barrio Escalante: el trabajo flexible como antesala al goce del ocio}

Hay una relación entre el trabajo y el ocio, que ya ha sido explicada en este documento y esta vinculación o relación es clara en el caso de la determinación temporal de barrio Escalante. Para abordar el ocio como experiencia, es imperativo introducirlo por medio de la vivencia del trabajo; por ello, lo prime- 
20. Es necesario subrayar un característica ocupacional que se refleja con claridad en el diagnóstico poblacional, que se realizar en las primeras secciones del este informe, en donde se apunta que la mayoría de las y los habitantes de barrio Escalante tienen puestos a nivel directivo, de la administración pública, y en las empresas privadas, así como también a nivel profesional, científico e intelectual, que representa el $62.5 \%$ de todos sus habitantes (INEC 2012). ro que se puede sostener a manera de tesis, es que los habitantes de barrio Escalante ejercitan una experiencia del tiempo que resguarda un ejercicio de autonomía y voluntad de poder relativa en relación con su trabajo y el ocio.

Su experiencia laboral es definida, por muchos de ellos, como actividad freelance. La temporalidad dentro de esta condición se presenta difusa. Su estructura tiende hacia la flexibilidad o la plasticidad y esto es de esperarse cuando los habitantes que animan la vida del barrio son muchos propietarios de negocios o profesionales liberales; son personas que se reconocen asimismo como líderes de la comunidad, emprendedores, interventoras o gestoras en el sector artístico, arquitectos, ingenieros, empresarias turísticas, relacionistas públicos, diseñadores gráficos, profesores universitarios o investigadores académicos o bien consultores ${ }^{20}$.

Entonces, ahora yo mando correos a las 2:00 a.m., porque estoy en la pensadera. Entonces, mando correos a la una de la mañana, dos, tres... hoy fue a las 4 a.m. que me desperté (Sandra 2012).

El tiempo de la actividad del trabajo se presenta en horas no habituales. En este relato, su temporalidad es la madrugada y esta actividad "sorprende" ya no en la oficina sino en su vivienda, en su hogar. Gerardo da pista de lo que sustenta la forma de trabajo de Sandra (2012): "mucho profesional tiene su casa acá y trabaja desde su casa" - inmediatamente después sentencia"¡es una tendencia!". Y la afirmación engloba el fenómeno que se verifica con los casos de Santiago, joven profesional que trabaja en una universidad pública entre semana y los fines se dedica a su negocio personal; o bien, José Pablo, quien administra su propia empresa de ingeniería en software ubicada en la parte frontal de su vivienda.

...la casa es un espacio de trabajo. Yo hago reuniones aquí a veces [...] también ¡diay!, como trabajo en cultura todo es aquí también, me entiende, San José centro, es por aquí pasa casi todo... entonces, en ese sentido, todo me queda muy cerca... o sea la galería me queda cerquísima (Elena 2012).

Ellos llaman, a esta forma de trabajo, freelance y la describen como jornadas laborales de muchas horas ("de siete a siete"), las perciben muchas veces como abusivas, o bien como jornadas laborales cortas pero de una gran demanda e intensidad mental. El freelance contiene a la flexibilidad temporal 
del trabajo, pero también la flexibilidad espacial del tiempo de trabajo. Ambas caracterizan estas nuevas dinámicas propias de una organización social del trabajo propio de un capitalismo avanzado y practicado por hombres y mujeres profesionales o propietarios con un status de vida alto. El testimonio de Elena vuelve a ser clave para comprender el carácter de la experiencia, de este temporalidad de productividad flexible, sostiene: "tengo meses de producción, mucho trabajo y un mes sin hacer casi nada, como ahora [...] yo siento que vivo en una mini vacación"21.

21. A pesar de que el trabajo bajo el ritmo de la flexibilidad es descrito como abusivo o de Por lo tanto, el trabajo cede lugar al ocio y el ocio prepara al trabajo en la eta- un gran desgaste mental, es pa del tiempo de trabajo flexible el ocio se presenta como una "mini vacamuy común encontrar en las ción". Este hecho solo indica cómo se difuminan y se vuelven porosos los límites entre los tiempos y espacios del trabajo, el ocio y la vida doméstica. Se agencia una suerte de disrupción sobre el modo clásico de determinación del tiempo en el capitalismo industrial en donde el espacio y el tiempo del trabajo se localizaban con facilidad en la fábrica o la oficina. Esta era su norma; no obstante, la experiencia actual del tiempo productivo y de ocio se presentan en este escenario específico de barrio Escalante bajo una suerte de "lógicas" yuxtapuestas.

\section{El ocio como voluntad de poder}

Lo primero que se podría establecer, en relación con el ocio y su definición, al partir de las narrativas de las habitantes de barrio Escalante, es que el ocio estaría asociado al "tiempo que queda en que no se está trabajando" (Gerardo, 2012). Es el instante cuando se cumplió con todo el trabajo y se entregaron los productos esperados; por lo tanto, a la persona ya no se le demanda responsabilidad hacia otros; siendo así, el ocio se presenta como impasse, una indeterminación donde la persona realiza prácticas orientadas al goce, pero, a la vez, el impasse es una temporalidad ansiosa, que espera la respuesta al trabajo realizado, o bien la emergencia de nuevo trabajo (José Pablo 2012, Santiago, 2012, Sandra, 2012, Liliana, 2012 y Gustavo, 2012); en todo caso, el ocio resguarda un carácter un temporalidad residual y marginal, que deviene del tiempo de trabajo y esto último determina, al menos, una de sus condiciones de sujeción.

Pero, su condición residual no representa una temporalidad vacía e inactiva. Todo lo contrario, el ocio es colmado por una serie de actividades de orden recreativo, lúdico o de mero entretenimiento. De las narrativas de los habitantes fue posible reconstruir, al menos, tres tipos o formas de ocio. En los escenarios representados se despliega la vivencia del ocio como experiencia cotidiana (ver cuadro 4). 
Cuadro 4. Tipo de temporalidades del ocio en barrio Escalante

\begin{tabular}{|c|c|c|}
\hline $\begin{array}{l}\text { Tipo de } \\
\text { temporalidad }\end{array}$ & $\begin{array}{l}\text { Temporalidad } \\
\text { espacial }\end{array}$ & Carácter \\
\hline $\begin{array}{l}\text { Ocio bucólico- } \\
\text { cosmopolita }\end{array}$ & $\begin{array}{l}\text { Fuera de la ciudad: } \\
\text { espacialidad común } \\
\text { (paisaje) }\end{array}$ & $\begin{array}{l}\text { Supone la posibilidad de viajar a lo } \\
\text { interno o externamente de la nación } \\
\text { hacia: otras ciudades, la costa o la } \\
\text { montaña generalmente a sus propias } \\
\text { fincas. Alejarse del ritmo de la ciudad. }\end{array}$ \\
\hline $\begin{array}{l}\text { Ocio consumista- } \\
\text { hedonista }\end{array}$ & La ciudad (público) & $\begin{array}{l}\text { Supone el cuido del cuerpo, el } \\
\text { consumo masivo, la satisfacción del } \\
\text { gusto gastronómico, estético, cultural, } \\
\text { el goce del paisaje urbano, la fiesta y la } \\
\text { filantropía (voluntariado: en espacio } \\
\text { urbano marginalizados) }\end{array}$ \\
\hline Ocio-vida doméstica & Viviendas (privada) & $\begin{array}{l}\text { Supone el despliegue de actividades } \\
\text { lúdicas y creativas: como cocinar, } \\
\text { bordar, pintar, decorar interiores, } \\
\text { arreglar o iniciar proyectos de } \\
\text { remodelación o construcción del } \\
\text { espacio o relajarse leyendo un artículo } \\
\text { de internet, leer un libro o el periódico o } \\
\text { simplemente desenfadarse en la huerta } \\
\text { urbana o el jardín interno de la } \\
\text { vivienda. }\end{array}$ \\
\hline
\end{tabular}

Fuente: Entrevistas a habitantes de barrio Escalante

El primero de estos escenarios es lejano al barrio. Se mueve entre una imagen tendencialmente bucólica, o bien en el otro extremo cosmopolita. Así, surge la imagen de la playa o el viaje a un paraje montañoso o la visita a la finca -la huida del paisaje y ambiente urbano-, o bien la posibilidad simplemente de alistar el equipaje abordar un avión, salir de la nación y transformarse en un paseante en otras ciudades:

Tengo vacaciones. Viajo una o dos veces al año y eso para mí es la vacación... Me voy a la playa (Elena 2012).

...estoy ahorrando, planeando viaje, me voy un mes

a Europa. No me amarra tampoco la casa (Sandra 2012).

El tiempo de ocio vuelve a ser un objeto sobre el que se ejerce voluntad de poder, una autonomía de elección y sirve, a su vez, para realizar una manifestación de desarraigo. El hogar no significa una atadura. Más bien, se expresa una independencia sobre él. El segundo escenario se presenta de ma- 
nera más inmediata y accesible. Es el barrio y, ampliado el horizonte de proyección, la ciudad de San José; en este caso, el tiempo de ocio es utilizado para ejercitar el cuerpo jugando al tenis, practicando voleibol, taekwondo o correr en una banda caminadora en un gimnasio o bien, paseando entre las calles y avenidas de la ciudad accediendo a su vida comercial, cafés, restaurantes, malles o, finalmente, tan solo tomando licor en la noche en el antiguo bar Buenos Aires o comprando un vino en un super market cercano para ir a compartir la noche con amigos sentados o recostados en el césped del hermoso parque Francia.

Pero, la ciudad y el barrio no solo son refugios para un ocio relacionado con actividades orientadas al cuido del cuerpo, participación espectáculos de masas o el consumo de mercancías, sino también el tiempo de ocio representa un momento propicio para actividades ligadas al campo de la cultural y el arte; por ejemplo: la feria de productos orgánicos en barrio Aranjuez, las Ferias del Arte, el City Tour o el Transitarte o a la Feria de Libro de la Aduana, exposiciones de arte o a las obras que se exhibe la Compañía Nacional de Teatro, o bien los fines de semana algunos de sus habitantes disponen de su tiempo libre para dedicarse a un voluntariado (filantropía) en algún barrio urbano marginalizado.

Y los sábados trabajo voluntariamente. Es un voluntariado realmente, no sé si cabe, como trabajo según los parámetros nuestros. Para mí, no es un reto. Es tanto ocio como salud mental lo que hago con ellos, eh... y entonces lo que si es cierto es que me consume el sábado, un poco más de la mitad del día, pero la verdad, pero no, no es trabajo (Santiago 2012).

En este punto, Bourdieu (2013) señala que la distancia social real de un grupo a unos bienes debe integrar la distancia geográfica, que, a su vez, depende de la distribución del grupo en el espacio y, con mayor precisión, de su distribución con respecto al "centro de valores" económico y culturales; es decir, con respecto a París o las grandes metrópolis regionales (p. 139).

En el caso de barrio Escalante, esta observación teórica de Bourdieu cobra vida empírica. Escalante es un espacio barrial que, en su seno, resguarda una serie de espacios de alta cultura y poder político; por ejemplo, internos: Taller Nacional de Teatro, Taller Nacional de Danza, galerías de arte, museo Calderón Guardia, Centro Cultura Español, parque Francia, La Aduana, entre otros y externos: centro de poder político cultural -Ministerio de Cultura, Tribunal Supremo de Elecciones, Asamblea Legislativa, Biblioteca Nacional, etcétera. 
Permítase una breve digresión aquí. Barrio Cristo Rey emergerá, entonces, como su antítesis, como la otra cara de esa distancia social real en el espacio urbano josefino. Cristo Rey se presenta como un espacio segregado y estigmatizado territorialmente (Wacquant 2007). Esto significa la imposibilidad de contener o incluso estar muy cerca de centros de poder cultural, político o económico (Lefebvre 2013). La estigmatización y la segregación, así como la lejanía del consumo cultural, se revela en las narrativas de las personas que habitan el barrio:

Esto es lo que llaman los barrios del Sur (Dennis 2012).

...eran pocos, pero la gente se reunía en la Soda

Perla, Chamelo, El Cine Kit. ¿Ese donde quedaba el Cine

Kit? Diagonal a donde quedaba Teletica, actual comisaría de policía (Ernesto 2012).

Ambas narrativas refuerzan la segregación histórico-especial y la destrucción de espacios-histórico de ocio-reunión, que a lo sumo existen hoy como puntos de referencia de lo que fue Cristo Rey.

Retomando. El tercer escenario del ocio está resguardado en el espacio vital privado del hogar. Es el lugar para relajarse en la cocina, para leer el periódico o un artículo por la internet, bordar o tomar un pincel y pintar, prender la televisión y mirar la programación que transmite el cable o dedicarse arreglar o dedicarse a remodelaciones para el espacio interno o construir mesas y sillones o sentarse a dibujar planos, o tocar el piano o la guitarra, cultivar una pequeña huerta urbana o relajarse en el jardín:

Yo, en mi casa vivo en el jardín, prácticamente [...] almuerzo, paso los espacios que puedo libre; es muy bonito [...] El jardín es como un sótano que tengo, me entendés, y después tengo el jardín donde voy haciendo las orquídeas, lo que fuera... Es muy tranquilo (Gerardo 2012).

El espacio vital de la casa se convierte en unidades urbanas, suerte de refugio para alejarse del ritmo cotidiano de la labores, de las responsabilidades, suspender el ritmo de las oficinas y otros negocios que han invadido el barrio, rehuir del trajín vehicular de la ciudad luego de ir a visitar clientes o donde se descansa de la entrega de consultorías. 
La estructura del tiempo de trabajo, que se delineó con el dato cualitativo, se despliega en la riqueza de su textura, de sus detalles, como ya se ha precisado, el tiempo de trabajo flexible se dispone en ruptura con una temporalidad, que se inserta en estructuras rígidas de horarios institucionalizados. Su norma es la flexibilidad. Su ubicación temporal-espacial transgrede los lugares socialmente dispuestos para el intercambio del tiempo de trabajo y se disponen a penetrar e instalarse en el mismo espacio-temporal de la vida cotidiana doméstica. A veces, los habitantes perciben que enfrentan horarios indeterminados, que trabajan más de lo debido, pero como se comprobó tienen una relativa voluntad de poder sobre el tiempo, ejercen una autonomía y gobiernan en el uso e intercambio.

Además de este gobierno relativo de su tiempo, esta suerte de derecho al tiempo, que les otorga ciertos grados de libertad en la forma y el grado de su intercambio y uso, presenta otra peculiaridad relevante. En los habitantes de barrio Escalante hay no solo un ejercicio de voluntad de poder sobre su temporalidad, sino también esa voluntad de poder sobre su tiempo se extiende. En algunos de los casos analizados, se trata de una voluntad de poder de apropiación sobre el tiempo de otras personas, que no habitan su espacio barrial.

a mí me sobra tiempo del mensajero aquí [...] Me sobran tiempo de las secretarias entonces que si ocupan algo de eso, yo les puedo ayudar (José Pablo 2012).

Sí, pero con ella, pues nos turnamos. Cuando estoy solo si es demasiado, pero con ella, pues, por lo menos, yo descanso (Gerardo 2012).

Ese tiempo sobrante es un tiempo extraído de otro (la secretaria, el mensajero, la ayudante del pulpería); ese tiempo del que dispone José Pablo o Gerardo ya no rige, en términos formales, la voluntad o los deseos de su propietario original. Sobre él rigen los deseos y las necesidades de sus compradores. Este fenómeno dirige la mirada hacia las lógicas de intercambio temporal del propio barrio donde hay habitantes que no solo ejercen una autonomía sobre su tiempo, sino también se comportan como compradores del tiempo de los otros, del cual disponen como excedente de su tiempo "natural" diario que puede ser cedido; por ejemplo, a las organizaciones barriales o para su propio descanso 22 .

22. Es importarte señalar la descripción gótica de Marx, cuando describe en el siglo XIX la relación de intercambio entre el capitalista y los trabajadores: El capital es trabajo muerto que no sabe alimentarse, como los vampiros, más que chupando trabajo vivo, y que vive más cuanto más trabajo vivo chupa. El tiempo durante el cual trabaja el obrero es el tiempo durante el que el capitalista consume la fuerza

Esta economía política del tiempo cotidiano posibilita trazar la hipótesis de de trabajo que compró. Y el que el goce del tiempo y del ocio, como voluntad de poder sobre el tiempo, obrero que emplea para sí su

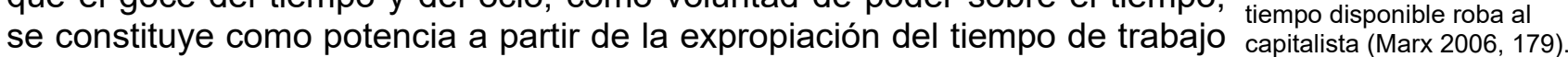


23. En este punto resulta necesario apuntar una tesis de Elias en relación con la superación de la dicotomía tiempo y espacio o espacio tiempo. Esta señalaría que el espacio y el tiempo son, en principio, símbolos conceptuales de ciertos tipos de actividades e instituciones sociales; es decir, permiten a las personas orientarse ante $y$ entre posiciones o distancias entre posiciones. El espacio es una síntesis conceptual que responde a normas fijas y el tiempo es una síntesis que responde a normas móviles: "Lo que a este respecto hay que decir puede expresarse con palabras más o menos sencillas: todo cambio en el espacio es un cambio en el tiempo, y todo cambio en el tiempo es un cambio en el espacio" (Elias 2013, 118). La reunificación del tiempoespacio -explica Elias- ya fue demostrada por A. Einstein y $\mathrm{H}$. Minkowski con el continuum cuatridimensional. Un ejemplo cotidiano y, por tanto, cercano, de esta reunificación del tiempo y el espacio lo simboliza el reloj de agujas. Si se mira, este simula la representación del desplazamiento de la tierra alrededor del sol: un cuerpo celeste que se mueve alrededor de otro cuerpo celestes. El tiempo y el espacio se reunifican por la actividad práctica (la praxis): el movimiento, el cambio infatigable son la condición de la realidad físico natural y físico social. de otras personas (individuos o sujetos que son externos -extranjeros- al barrio), quienes podrían no disponer de ese derecho al tiempo que ejercen los habitantes de Escalante; además, resalta superlativamente la impronta empírica de un tiempo centrado en el valor de intercambio por sobre la de un tiempo de uso-útil.

Ahora bien, la contra cara a ese gobierno del tiempo, como un recurso, o bien propio, es la experiencia del tiempo alienado, la cual se formula en la experiencia y la vivencia del tiempo de las personas que habitan barrio Cristo Rey.

\section{Las rutinas del tiempo como temporalidad alienada}

La antítesis del gobierno del tiempo del que gozan los habitantes de Escalante lo encarnan las personas que viven en barrio Cristo Rey. Si en barrio Escalante la comprensión del ocio significó comprender de entrada el tiempo de trabajo flexible, para el caso de barrio Cristo Rey, la lógica se invierte. Por lo tanto, es necesario, primero, entender qué representa el tiempo "libre" para adentrarse en el significado y el lugar del trabajo en la vida cotidiana de barrio popular de la ciudad de San José.

Si barrio Escalante, como espacio social, contiene el tiempo flexible del capitalismo neoliberal, barrio Cristo Rey es aún hoy la expresión del tiempo rutinario y disciplinario del "antiguo" capitalismo industrial; es decir, vivir en el capitalismo neoliberal se transforma en un rasgo simbólico de distinción sociocultural y socioeconómico de la clase. Es en este espacio-tiempo ${ }^{23}$ de barrio Cristo Rey, donde se torna concreto y verdadero aquel tiempo libre u ocio presentado como un acontecimiento extraordinario por el dato cuantitativo. El carácter del ocio y su horizonte queda descrito con crudeza por Dennis:

Sí, sí salgo los sábados agarro a mis hijos que voy a La Sabana y así, trato de compartir más que todo los sábados, porque yo sé que entre semana, muy, muy poco y los domingos muy, muy difícil, porque sinceramente yo los domingos los agarro para estar en la casa, juego con ellos y todo, pero muy pausado, porque yo sé que ya llega el lunes trabajar y todo (Dennis 2012).

Otro habitante del barrio, Federico, sostiene que el ocio es "irse a dormir". El ocio parece ser una ausencia entre semana y apenas si asoma como presencia los fines de semana, pero no como tiempo de disfrute. Parece que nace fundamentalmente condicionado por la temporalidad agotadora del trabajo. El 
ocio, como lo vislumbra Dennis (2012), nunca se libera de la coerción de un tiempo productivo; es decir, padece de la angustia del "nuevo" trabajo.

El ocio, en este caso, tampoco es el momento para la creatividad, el consumo, la filantropía, la voluntad de poder; es fundamentalmente un tiempo escaso que se dispone para fortalecer los lazos familiares, dormir o bien un tiempo para la quietud, el no movimiento (muy pausado), en su límite la angustia del lunes: "trabajar y todo". Parece que a las personas, que viven en barrio Cristo Rey, les es imposible aludir al ocio sin olvidar la dura realidad del trabajo. Esto se aclara al estudiar y analizar sus rutinas cotidianas de vida.

\section{La asfixia rutinaria del tiempo de trabajo}

La vida en el barrio Cristo Rey inicia desde buena mañana. Si el día que se escogiera resultara ser un lunes, una persona enterada del ciclo temporal del mundo del trabajo de Cristo Rey comprendería que una parte importante de sus habitantes habría trabajado el día domingo. Las jornadas semanales de trabajo de las personas que habitan en Cristo Rey inician un lunes y terminan un sábado y otras van de domingo a domingo. Estas últimas no conocen término de descanso. Se presentan como temporalidades de trabajo sempiternas.

Las personas habitantes del barrio, en su mayoría, son trabajadores artesanales y sus oficios no se concentran en gasto de energía "intelectual". El carácter del trabajo exige labores artesanales y manuales con gran desgaste de fuerza física; lo anterior, a contra punto de barrio Escalante, permitió construir no una tipología sobre el ocio para las y los habitantes de barrio Cristo Rey sino una tipología de tres ritmos o rutinas asociadas directamente con la vida del trabajo. El cuadro 5 presenta, de manera sintética, las tres rutinas de trabajo que se elaboraron a partir de los relatos de varios de sus habitantes.

Dennis representa la primera rutina. Él trabaja desde que tiene nueve años. Así aprendió su oficio, de enderezado y pintura, en el taller de su padre ubicado también en barrio Cristo Rey. Hoy, es trabajador de la Purdy Motors, representante de la transnacional japonesa de automóviles Toyota. Él define su trabajo como pesado, exigente y agotado. Dicho cansancio se prolonga de 7:00 a.m. a 5:30 p.m. Dennis se desplaza caminando tanto a la entrada como a la salida de su trabajo.

¡Ajá! Igual a la venida. Es como un poco más rápido, sinceramente, es más rápido porque usted va agarra el bus y, Dios guarde, para llegar ahí el único que lo deja más cerca para llegar ahí es León XIII. El de la León XIII pasa por ahí o en el centro de San José, dan una vuelta que, 
sinceramente, vea agarro el bus y que yo me voy caminando y llego yo más primero ( $(\mathrm{ic})$ y entonces, sinceramente, llega usted más rápido hasta más cansado es para uno y todo y uno no puede llegar tarde, Dios guarde, es muy importante no lo dejan a uno (Dennis 2012).

\section{Cuadro 5. Síntesis de rutinas cotidianas de trabajo en barrio Cristo Rey}

\begin{tabular}{|c|c|c|}
\hline Ritmo temporal & $\begin{array}{l}\text { Determinación } \\
\text { temporal }\end{array}$ & Cualidad de la rutina cotidiana \\
\hline $\begin{array}{l}\text { La rutina del } \\
\text { Obrero }\end{array}$ & $\begin{array}{l}\text { Tiempo rutinario: } \\
\text { reloj }\end{array}$ & $\begin{array}{l}\text { Levantarse, alimentarse, salir del hogar, } \\
\text { caminar aprisa por la ciudad, no tomar el bus, } \\
\text { presas, arriar a la compañía, parar el } \\
\text { dispositivo temporal, marcar la tarjeta de } \\
\text { trabajo, evitar el castigo, realizar un trabajo } \\
\text { pesado hasta el cansancio físico, hora de } \\
\text { salida, marca de salida, caminar por la ciudad, } \\
\text { llegar a su hogar, comer y dormir para volver } \\
\text { a levantarse al día siguiente. }\end{array}$ \\
\hline $\begin{array}{l}\text { La rutina del } \\
\text { agobio }\end{array}$ & $\begin{array}{l}\text { Tiempo rutinario: } \\
\text { calendario anual }\end{array}$ & $\begin{array}{l}\text { Despertarse a las cinco de la mañana, } \\
\text { desayuno, abrir la puerta del bazar a las seis } \\
\text { de la mañana, vende laminillas, refrescos, } \\
\text { tarjetas de teléfono u otros productos, } \\
\text { interines, vonversar con algún cliente, vecina } \\
\text { o amiga, al aproximarse la noche cerrar las } \\
\text { puertas del bazar-pulpería, comer algo y } \\
\text { acostarse a dormir. }\end{array}$ \\
\hline $\begin{array}{l}\text { La síntesis } \\
\text { productiva/repro } \\
\text { ductiva femenina }\end{array}$ & $\begin{array}{c}\text { Tiempo rutinario: } \\
\text { día }\end{array}$ & $\begin{array}{l}\text { Inicia muy temprano en la mañana,se } \\
\text { despierta, se baña, alista el desayuno, la } \\
\text { merienda y almuerzos de los hijos(as) y } \\
\text { esposo, abre la peluquería (o va al trabajo); } \\
\text { trabaja, sale de su trabajo, va hacia su hogar, } \\
\text { hace la cena y el almuerzo del esposo del día } \\
\text { siguiente, quizás barre, lava, plancha o limpia } \\
\text { un poco la cocina, en suma: hace los } \\
\text { quehaceres y deja todo listo, tal vez mire la } \\
\text { televisión y al final del día se duerme... }\end{array}$ \\
\hline
\end{tabular}

Fuente: Entrevistas a habitantes de barrio Cristo Rey

Caminar es un medio de desplazamiento por la ciudad más efectivo que abordar un bus, subraya Dennis (2012), y es práctico en dos sentidos. El primero de ellos se relaciona con hacer del día de trabajo una jornada menos agotadora (viajar en bus es estresante por las presas) y segundo por librarse 
de llegar tarde como lo evidencia el fragmento citado. No puede llegar tarde; por lo tanto, el hecho de desplazarse caminando desde su casa hasta el trabajo le alivia la preocupación de llegar tarde y que el reloj marcador de entrada y salida registre un ingreso tardío al trabajo; caminar le permite vencer el dispositivo de control disciplinar que representa el reloj. De esta forma, Dennis logra cumplir con su horario de 7:30 p.m. a 5:30 p.m. y evitar la posibilidad del despido.

La segunda rutina la encarna Federico. Su ritmo cotidiano se distingue de la de Dennis por un hecho particular. Federico no trabaja para ninguna transnacional. Él es dueño del bazar-pulpería de Cristo Rey. La "naturaleza" del trabajo de Federico es la de brindar un servicio. Sus actividades no "giran" en torno a un trabajo artesanal-físico.

¿Entonces empiezo que sé yo?... esto es lo básico de referencia de este negocio (señala las láminas educativas) [...] Es el internet del barrio [...]... es más que todo esto siempre ha sido un bazar... con venta de artículos de librería, hasta ahora es que hemos tratado de incursionar en la cuestión de frescos. [....] Para ver si algo mueve un poco más, para recoger un cinco más... que sé yo las tarjetas telefónicas, que sé yo algo más cosas nuevas (Federico 2012).

El bazar es, ahora, también, pulpería. La motivación es clara ante la necesidad de recoger algo más de dinero. En realidad, este es un negocio al que se le dedica mucho tiempo mucho trabajo... se abre de lunes a sábado y el domingo. Se abre igual y cierra un poquito más temprano (Federico, 2012); continúa Federico en relación con la jornada de trabajo: "aquí se abre de 6 de la mañana a 7 de la noche" (Federico, 2012) y los domingos "de 6 de la mañana a 3 de la tarde" (Federico, 2012). Son 78 horas de trabajo de lunes a domingo y 8 horas del domingo suman 86 horas de trabajo a la semana. El día "libre" de descanso es prácticamente inexistente.

Frente a las 86 horas de trabajo a la semana, se levanta un trabajo que día tras día ha sido el "mismo" durante largos e interminables décadas. Federico se sabe su oficio de memoria: "es una situación que tiene mucho, ya tenemos 30 años, ya hasta que esta cuadrado uno, ya hasta me siento cuadrado" (Federico, 2012). Es una rutina que se presenta como agobiante, que ha iniciado y acabado, una y otra vez, desde 1983. 
24. La entrevista a Federico se realizó en compañía de don Cholo, viejo militante del Partido Vanguardia Popular.
Su trabajo imposibilita el despliegue de otras habilidades, capacidades y potencialidades. El oficio lo aprisiona, lo encierra en suerte de estructura simbolizada en la figura de un cuadrado que imposibilita la creatividad, la imaginación o la emergencia de una salida. Federico expresa querer poder "romper el naipe"24; sin embargo, don Chalo (2012) no tarda en señalarle y recordarle a su yerno que tal posibilidad es impensable: "él ya no tiene otro camino".

Las dos rutinas antes descritas evidencian ya una apropiación muy singular del tiempo por parte de las personas que las encarnan. En ellas, el tiempo libre de ocio no parece estar presente en la semana laboral y apenas se asoma el fin de semana. El trabajo como actividad productiva se despliega como una totalidad que presiona al ocio y aplasta la voluntad de poder sobre el tiempo de estos hombres.

El caso de Ariana, tercera rutina, tampoco desmonta la lógica del agobio que impone cotidianamente el tiempo de trabajo; sin embargo, Ariana, a diferencia de Federico y Dennis, es mujer y el género irrumpe como factor que particulariza radicalmente el ritmo de la vida cotidiana que rige sus condiciones materiales de existencia.

Entre semana mi horario era hasta las 11 de la noche y, dependiendo del trabajo, si tenías citas a las 5 o 6 de la mañana estaba trabajando. Eso dependía de los clientes que tenía, más aún para época de graduaciones, verdad, pero los domingos entro a las 8 de la mañana y salgo a las 4 de la tarde (Ariana 2012).

El ritmo cotidiano que describe Ariana es notoriamente más demandante que el de sus vecinos hombres. Trabajaba de lunes a domingo, a veces, con horarios hilarantes de 5:00 a.m. o 6:00 a.m. a 11:00 p.m. (días de 17 a 18 horas de trabajo que se extiende incluso hasta los domingos).

Pero, Ariana no tiene un solo trabajo: "yo espacio, espacio mucho no tengo, porque yo tengo la peluquería y aparte, doy clases en un colegio los fines de semana (Ariana 2012). Sostiene no tener espacio, pero tampoco cuenta con tiempo, puesto que es absorbido por la necesidad del trabajo, de intercambiar su tiempo, pero este ritmo frenético no se detiene. Ariana, además, como mujer debe asumir los roles impuestos culturalmente supuesto de madre y esposa: "me levantó muy temprano dejó las cosas listas y mis hijos nada más se sirven... para regresar a mi casa y tener los quehaceres y después en ese momento la sala hasta ahí" (Ariana 2012).

El tiempo de trabajo y el tiempo de la vida doméstica, del trabajo que no remunerado, vistos desde la intersección del género y la clase trazan, al me- 
nos, tres distinciones analíticas: la primera, en ninguno de los relatos descritos y analizados de los hombres se retratan labores relacionadas con el mundo cotidiano de la vida doméstica; en cambio, y acá se presenta la segunda distinción, el mundo de la vida doméstica sí se percibe en el caso de Ariana, ${ }^{25}$ un horizonte "exterior" cotidiano que asigna un sistema nuevo de labores. Implica el estar: "limpiando, barriendo, cocinando, atendiendo, llevando al nieto a la escuela y llevarlos a la plaza" (Ariana, 2012) y se transita a la tercera distinción, las mujeres de barrio Cristo Rey son trabajadoras remuneradas y no remuneradas, pero en el marco de la cultura patriarcal naturalizada, al casarse y reproducir la familia, en su "destino social" está inscrito un imperativo a priori: ser amas de casa y madres, lo que significa implicarse en la responsabilidad de la reproducción del mundo de la vida doméstica.

La mujer en esta situación está sujetada temporalmente. Su tiempo vital es arrancado por el mundo de la vida doméstica y el mundo del trabajo; no puede escapar de ellos, el mundo de trabajo se impone como necesidad económica y social en tanto el mundo de la vida doméstica se le impone bajo un pseudo imperativo cultural -patriarcal- que le exige cumplir con las labores de cuido ${ }^{26}$ y servicio hacia los nietos, los hijos y esposo. ${ }^{27}$

Del estudio del intercambio y uso del tiempo cotidiano de las mujeres, ilustrado por el caso de Ariana, se desprende con claridad una tercera rutina en la división social del tiempo de trabajo determinado por la condición de sexo-género. Es en las condiciones materiales de existencias de las mujeres, donde se fundamenta la reproducción de la arquitectura temporal del mundo de la vida cotidiana en su totalidad; por tanto, de esta esfera de los cuidados, de lo no remunerado, la base de posibilidad del trabajo remunerado y en el fin de este marca el retorno a la labor de los cuidados.

La resultante es un ritmo, un ciclo implacable que dibuja una existencia cotidiana que somete, explota y reprime a las mujeres. Además, dicha realidad se impone naturalizada, ideológica y culturalmente se presenta infranqueable; por tanto, resulta difícil de poder tomar distancia para reflexionarla y cuestionarla dado que no cesa nunca. Así, es posible de nuevo vislumbrar con absoluta nitidez que el trabajo no remunerado es el arché que reconstituye una y otra vez la reproducción ampliada de un mundo cotidiano capitalista y patriarcal ${ }^{28}$.

En resumen, el trabajo es una labor de dolor, pesadez, agotamiento y exigencia, una rutina que se repite hace 30 años, con jornadas de trabajo que se disponen largas, extenuantes y casi interminables para los hombres y mujeres. El tiempo de trabajo transita con este halo, pero, para el caso particular de la mujer, su jornada de trabajo-labor se presenta como si fuera infinita. El trabajo-labor no tiene fin; no importa si es tiempo-público o tiempo privado. Su fórmula es: servir, cuidar, trabajar, reproducción-producción. El sistema temporal de la sociedad capitalista-patriarcal es simplemente implacable. No cesa para los hombres y las mujeres habitantes de barrio Cristo Rey.
25. También, en el de otras mujeres; por ejemplo, Juliana, mujer, y adulta mayor.

26. Su servicio y cuido es por la reproducción de las fuerzas intelectuales, laborales y

libidinales; en esta dinámica de sobre explotación económica y sobre represión cultural, deben las mujeres lograr la auto reproducción de sus fuerzas vitales.

27. Se advierte que se habla de nietos, hijos y esposos por que las mujeres entrevistadas. En barrio Cristo Rey nunca señalaron el cuido y el servicio a nietas, hijas u otras mujeres, lo cual dice mucho acerca de la lógica y la racionalidad patriarcal que orienta los roles de género en las labores de cuido y servicio. Esta misma lógica patriarcal es más sutil para el caso de barrio Escalante.

28. Tiene razón Silvia Federici $(2020,253)$ al señalar que mirar los sistemas de reproducción-reproducción, desde el lugar de la mujer (desde la posición sexogénero), avisa no solo relaciones de poder, sino también experiencias y visiones cotidianas cualitativamente diferentes. 
29. La lógica hegemónica que determinan -siguiendo a Elias (2013) -esta arquitectura temporal es el ritmo de producción-reproducción del individuo capitalista. Entre ellas como "mediación" se cola el ocio.

\section{Conclusiones}

En relación con los hallazgos resultantes de la aplicación de esta propuesta analítica a los barrios en estudio, se encuentra que ambos espacios urbanos barriales presenten una configuración de lo que ha sido definido como arquitectura del tiempo cotidiano ${ }^{29}$ muy semejante. Dicha estructura estaría constituida por tres grandes esferas: un tiempo de trabajo, un tiempo doméstico y un tiempo residual: ocio o tiempo "libre".

Pero, si de esa arquitectura temporal encontramos elementos comunes o semejantes entre los entornos barriales; en esa misma estructura, en su despliegue singular, en cada uno de los barrios, se desprenden diferencias cuando se estudiaba a partir de la intersección de las categorías de clase y género. Para ilustrar la relación tiempo-clase social, los habitantes de barrio Escalante, en general, tienen más estudio, son profesionales con posgrados y en muchos casos dueños de negocios propios. En sus narrativas se evidencia posibilidades de asumir el gobierno de su tiempo, disfrutan de cierta autonomía relativa en relación con su tiempo y se saben poseedores del tiempo de otras personas, sus trabajadores o trabajadoras. Se comportan como compradores del tiempo; se apropia de un tiempo ajeno a ellos y ellas.

El caso de los habitantes de barrio Cristo Rey es el opuesto. Su tiempo de ocio es algo menor. Los hombres y las mujeres trabajan más que sus pares de barrio Escalante. En las narrativas se desliza la demanda agobiante de su trabajo, el cual, muchas veces, les consume los siete días de la semana. No expresan una autonomía o gobierno del tiempo y sus ratos de ocios los utilizan para pasar tiempo con su familia y descansar ante la angustia del inicio de la semana de trabajo. Se comportan como venderos en el mercado o economía del tiempo de trabajo.

En relación con el género y el tiempo: la vida doméstica de los habitantes de barrio Cristo Rey y de barrio Escalante es especialmente agotadora para las mujeres en ambos espacios. Las mujeres se encargan centralmente del cuido de personas, la alimentación y la limpieza, mientras que los hombres todavía asumen el rol masculino de trabajar, reparar y dar mantenimiento a la vivienda. Este patrón es prácticamente idéntico en ambos barrios.

Las labores no remuneradas del hogar las resuelve aún hoy como un deber la mujer; sin duda, tiene implicaciones en la vida pública, en el espacio público-político, en su propia vida y autocuido, en las posibilidades de poder desplegarse y desarrollar todas sus capacidades y potencias como personas, lleva razón de Beauvoir (1949), cuando apunta que, cuando señala que a la mujer se le demanda la conservación de la especie y el trazo de la inmanencia, que garantiza el ritmo continuo de los días en la permanencia del hogar.

Lo anterior deviene en otros elementos conclusivos que iluminan procesos interesantes que exceden las posibilidades de este trabajo, puntualmente los datos y el análisis demuestra dos lógicas en coexistencia dialéctica, una tem- 
poralidad propia del moderno capitalismo tardío neoliberal, flexible, fluido que descoloca a sus agentes de los espacios sociales tradicionales de producción material y simbólica de mercancías, servicios y artefactos culturales. Este tiempo flexible está en posesión de cierta clase de gente, como un privilegio y una voluntad de poder sobre el tiempo, en este caso, de las personas que habitan barrio Escalante, quienes se presentan como sus representantes.

El otro, un tiempo que sobreviene como cifra "arqueológica" del capitalismo benefactor e industrial, expresa una rutina y disciplinas rígidas; también, trayectorias plausibles que condensan oficios que, muchas veces, se heredan de unas personas a otras y se vuelven constitutivos de sus subjetividades, identidades y biografías personales. Este tiempo productivo encuentra lugares precisos ya no necesariamente yuxtapuestos en el hogar, sino en la fábrica o la oficina burocratizada, etc. En este caso, como se apreció, son los habitantes de barrio Cristo Rey, quienes dan lugar a este dominio temporal sobre el cual no tienen voluntad, sino más bien este ritmo se le impone, los presiona y determina por agotarlos.

En términos teórico-analíticos, es posible trazar el argumento y supuesto de que el tiempo flexibilizado propio del capitalismo tardío neoliberal y posmoderno, que se expresa en el espacio urbano social de Escalante, se constituye como privilegio y posibilidad en tanto condiciona, sujeta y se apropia del tiempo rutinario, disciplinar y agobiante, expresado en la relacionalidad temporal cotidiana que ejemplifica Cristo Rey; es decir, el tiempo que venden las personas trabajadoras deviene en condición de posibilidad para el ejercicio de una voluntad de poder relativa sobre el tiempo apropiado excedente del cual gozan ciertas personas, grupos y clases sociales altas. Esta tensión y dialéctica se da en el escenario de una economía del tiempo que sobre determina el valor de cambio por sobre el valor de uso y soporta este proceso en su evolución. Todo esto debe ser necesariamente investigado en un estudio más amplio y preciso sobre este fenómeno.

Finalmente, este panorama traza una interrogante en relación con las consecuencias en la salud psicosocial y la salud física de personas que enfrentan diariamente este tipo de dinámicas cotidianas altamente estresantes y agotadoras $^{30}$. También, apunta a otro escenario del orden de la política y lo político en relación con la ciudad. Lefebvre (1969) sostenía la importancia de la apropiación como forma de luchar contra la dominación. La apropiación supone la lucha por el derecho negado a la ciudad (neoliberal) como espacio para la apropiación estética, cultural y política, como espacio vital para la creación de nuevas formas de habitar por parte de los individuos, grupos y clases segregadas y estigmatizadas (Harvey s.f. y Lefebvre 1969).

Sin embargo, el estudio del tiempo urbano realizado plantearía, al menos, la siguiente interrogante en relación con toda lucha por la apropiación por el espacio urbano de la ciudad: ¿acaso no supondría necesariamente un esfuerzo

30. Por ejemplo, en relación con la salud mental múltiples factores se asocian con enfermedades mentales o con la carestía de salud en general, entre ellos se mencionan los siguientes: falta de acceso a la cobertura de necesidades básicas, sobrepoblación (hacinamiento), estrés en la vida cotidiana, condiciones adversas de trabajo, pobreza, marginación, miseria,

precarización de las condiciones de trabajo, etc. (Barquero, Leandro y Sotela 2013). 
teórico-práctico por reflexionar el derecho por la apropiación del tiempo? y si este análisis sobre la distribución y lucha por la apropiación del tiempo no incluye la relación crítica de la clase con el género, ¿no se correría el peligro de mantener cerradas las puertas de la ciudad a todas aquellas experiencias y prácticas que transgredan el carácter masculino, patriarcal y autoritario que atraviesa al poder del capital y al poder de la política?

\section{Bibliografía}

Álvarez, Eduardo. 1996. Onerismo bajo la fragmentación: proyecto de vivienda en la altura con comercio en la planta baja en el Barrio Cristo Rey. Tesis para optar al grado de Licenciatura en Arquitectura. Universidad del Diseño: San José, Costa Rica

Barquero, Patricia, Mauricio Leandro y Gabriela Sotela. 2013. «Determinantes socio ambientales de la salud». En Estado del Arte de la Investigación en Salud Mental en Costa Rica. Recuperado de: http:// www.kerwa.ucr.ac.cr/bitstream/handle/10669/8942/Estado\%20del \%20arte\%20de\%20la\%20investigaci\%C3\%B3n\%20en\%20salud $\% 20$ mental\%20en $\% 20$ Costa\%20Rica.pdf?sequence $=1$

Baudrillard, Jean. 1970. La sociedad del consumo. Sus mitos, sus estructuras. España: Plaza \& Janes.

Baudrillard, Jean. 1974([2009). Crítica de la economía política del signo. México: Siglo XXI.

Bauman, Zigmunt. 2006. Modernidad Líquida. Argentina: FCE.

Berman, Marshall. 1989. Todo lo sólido se desvance en el aire: La experiencia de la modernidad. Argentina: Siglo XXI.

Botey, Ana. 1999. El ferrocarril al Pacífico: un ente de regulación y desarrollo en crisis permanente. Anuario de Estudios Centroamericanos 25(1), 139-158.

Bourdieu, Pierre. 1979(2013). La Distinción: criterios y bases sociales del gusto. México: Taurus.

Carvajal, Guillermo. 2005. La ciudad de San José y la organización del espacio urbana en el valle central de Costa Rica. San José, Costa Rica: Editorial Librería Alma Mater. 
COF. 1978. Diagnóstico Social de los barrios Aguantafilo, Barrio Cuba, 15 de setiembre, Cristo Rey y Sagrada Familia en el Área Metropolitana de San José. Centro de Orientación de la Familia (COF). Costa Rica.

Cruz, Edgar. 1995. La vivencia de un encuentro cultural: proyecto habitacional en la altura productiva en Barrio Cristo Rey. Tesis para optar al grado de Licenciatura en Arquitectura. Universidad del Diseño: San José, Costa Rica

Díaz, Leticia y Esther Torrado. 2019. «El género y sus interseccionalidades desde una perspectiva sociológica e histórico-crítica en las narrativas autobiográficas de Angelou, Lorde y Davis». En Investigación feminista. Monografía: Legado afrodescendiente $y$ feminismo en los movimientossociales por la igualdad y no discrminación 9(2): 291-307.

De Beauvoir, Simon. 2005. El segundo sexo. España: Ediciones Cátedra.

Durán, María y Jesús Rogero. 2009. Cuadernos metodológicos: La investigación sobre el uso del tiempo. España: CIS.

Durán, María. 2006. El valor del tiempo. ¿Cuántas horas te faltan al día? España: Espasa.

Elias, Norbert. 2013. Sobre el tiempo. México: FCE.

Federici, Silvia. 2020. Rencantar el mundo. El feminismo y la política de los comunes. Madrid: Traficantes de sueños.

Harvey, David. s.f. El Derecho a la ciudad. Recuperado el 23 de enero de 2013, http://www.moviments.net/espaimarx/docs/6786f3c62fbf9021694f6e51c c07fe3c.pdf

Heller, Agnes. 2002. Sociología de la vida cotidiana. Barcelona: Ediciones Península.

INEC. 2011. Resultados Generales. Censo 2011 (X Censo Nacional de Población y VI de Vivienda). San José, Costa Rica: Instituto Nacional de Estadística y Censos de Costa Rica.

INEC. 2012. Indicadores Censales de Barrio Cristo Rey y Barrio Escalante. San José, Costa Rica: Instituto Nacional de Estadística y Censos de Costa Rica.

Jameson, Frederich. 1995. El posmodernismo o la lógica cultural del capitalismo avanzado. España: Ed. Paidós.

Kosík, Karel. 1967. Dialéctico de lo concreto. México: Grijalbo. 
Lefebvre, Henri. 1969. El derecho a la ciudad. Barcelona: Ediciones Península.

Lefebvre, Henri. 1972. La vida cotidiana en el mundo moderno. Madrid: Alianza.

Lefebvre, Henri. 2006. La presencia y la ausencia. Contribución a la teoría de las representaciones sociales. ( $2^{\circ} \mathrm{ed}$.). México: FCE.

Lefebvre, Henri. 2013. La producción social del espacio. España: Capitán Swing.

Marcuse, Herbert. 1970. Eros y civilización. España: Seix Barral.

Marcuse, Herbert. 1968. El hombre unidimensional. México: Editorial Planeta.

Marx, Carlos. 2006. El Capital, Tomo I: crítica a la economía política ( $\left.3^{\circ} \mathrm{ed}.\right)$. México: FCE.

Page, Mariano. 1996. Los usos del tiempo como indicadores de la discriminación entre géneros. España: Ministerio de Asuntos SocialesInstituto de la Mujer.

Quesada, Florencia. 2011. La modernización entre cafetales: San José, Costa Rica, 1880-1930. San José, Costa Rica: Editorial Universidad de Costa Rica.

Ramírez, Carlos y Jorge Rodríguez. 1999. Propuesta de rehabilitación urbana aplicación en el Barrio Cristo Rey. Tesis para optar al grado de licenciatura en Arquitectura. Universidad Central: San José Costa Rica.

Rodríguez, Oscar. 2000. Centro para el arte, la cultura y el deporte: Barrio Cristo Rey. Tesis para optar al grado de licenciatura en Arquitectura, Universidad Central: San José, Costa Rica.

Sandoval, Irma, Lidia González, Guiselle Rodríguez, y Laura Guzmán. 2011. Uso del tiempo en el Gran Área Metropolitana: una mirada cuantitativa del trabajo invisible de las mujeres. Costa Rica: INAMU.

Sennet, Richard. 2004. La corrosión del carácter: las consecuencias personales del trabajo en el nuevo capitalismo. Barcelona: Anagrama.

Solís, Julio y Paulo Coto. 2014. Convivencia urbana en San José. Un estudio sobre las prácticas cotidianas, las representaciones y proyecciones de las y los habitantes de barrio Cristo Rey y Escalante (2011-2013). Costa Rica: CICDE-UNED. 
Wacquant, Loïc. 2007. La estigmatización territorial en la edad de la marginalidad avanzada. Ciências Sociais Unisinos- Disponible en: http://www.redalyc.org/articulo.oa?id=93843301> ISSN 1519-705

Weber, Max. 2015. La ética protestante y el espíritu del capitalismo. España: Akal

Wright Mills, Charles. 1959 (2006). La imaginación Sociológica. México: FCE. 